\title{
DR. 2606
}

\section{Electron-Cyclotron Heating of Toroidal Plasma with Emphasis on Results from the ELMO Bumpy Torus (EBT)}

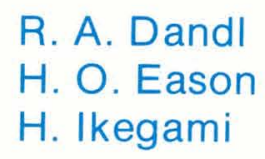

R. A. Dandl

H. O. Eason

H. Ikegami

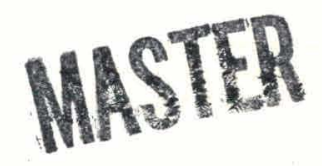

OAK RIDGE NATIONAL LABORATORY OPERATED BY UNION CARBIDE CORPORATION - FOR THE DEPARTMENT OF ENERGY 


\section{DISCLAIMER}

This report was prepared as an account of work sponsored by an agency of the United States Government. Neither the United States Government nor any agency Thereof, nor any of their employees, makes any warranty, express or implied, or assumes any legal liability or responsibility for the accuracy, completeness, or usefulness of any information, apparatus, product, or process disclosed, or represents that its use would not infringe privately owned rights. Reference herein to any specific commercial product, process, or service by trade name, trademark, manufacturer, or otherwise does not necessarily constitute or imply its endorsement, recommendation, or favoring by the United States Government or any agency thereof. The views and opinions of authors expressed herein do not necessarily state or reflect those of the United States Government or any agency thereof. 


\section{DISCLAIMER}

Portions of this document may be illegible in electronic image products. Images are produced from the best available original document. 


\section{Printed in the United States of America. Available from National Technical Information Service \\ U.S. Department of Commerce 5285 Port Royal Road, Springfield, Virginia 22161 \\ Price: Printed Copy $\$ 6.00$; Microfiche $\$ 3.00$}

This report was prepared as an account of work sponsored by an agency of the United States Government. Neither the United States Government nor any agency thereof, nor any of their employees, contractors, subcontractors, or their employees, makes any warranty, express or implied, nor assumes any legal liability or responsibility for any third party's use or the results of such use of any information, apparatus, product or process disclosed in this report, nor represents that its use by such third party would not infringe privately owned rights. 
ORNL/TM-6703

Dist. Category UC-20 a, d, f, g

Contract No. W-7405-eng-26

FUSION ENERGY DIVISION

ELECTRON-CYCLOTRON HEATING OF TOROIDAL PLASMA WITH EMPHASIS

ON RESULTS FROM THE ELMO BUMPY TORUS (EBT)

R. A. Dandl, H. O. Eason, and H. Ikegami

Date Published: May 1979

[This report was originally prepared for submission to Nuclear Fusion.]

Prepared by the OAK RIDGE NATIONAL LABORATORY

Oak Ridge, Tennesșee 37830

operated by

UNION CARBIDE CORPORATION

for the

DEPARTMENT OF ENERGY
NOTICE

This report was prepared as an account of work sponsored by the United States Gove rnment. Neither the

United States nor the United States Department of

Energy, nor any of their employees, nor any of their

contractors, subcontractors, or their employees, makes

any warranty, express or implied, or assumes any legal liability or responsibility for the accuracy, completeness or usefulness of any information, apparatus, product or process disclosed, or represents that its use would not infringe privately owned rights. 
i.

THIS PAGE

WAS INTENTIONALLY

LEFT BLANK 


\section{CONTENTS}

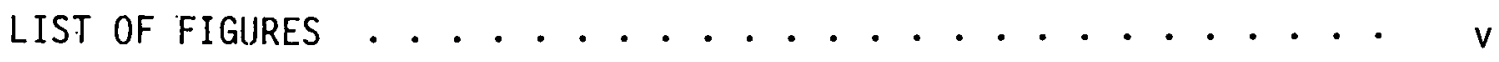

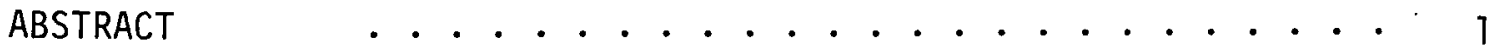

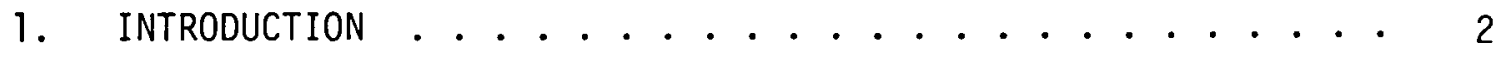

2. GENERAL ELECTRON-CYCLOTRON PLASMA HEATING CONSIDERATIONS • . 3

2.1 MICROWAVE COUPLING TO PLASMA . . . . . . . . 3

2.2 ELECTRON-CYCLOTRON HEATING RATE ......... 11

2.3 MICROWAVE HOT ELECTRON PLASMA INSTABILITIES . . . . . 14

3. MICROWAVE HEATING EXPERIMENTS .................... 16

3.1 MICROWAVE HEATING IN MAGNETIC MIRROR GEOMETRY . . . 16

3.2 RECENT MICROWAVE HEATING RESULTS IN TOKAMAKS . . . . 17

3.3 MICROWAVE HEATING IN THE ELMO BUMPY TORUS ...... 20

3.3.1 The ELMO Bumpy Torus (EBT) Experiment . . . . 20

3.3.2 Electron-Cyclotron Heating in EBT . . . . . 22

3.3.3 MHD Stability............. . . 24

3.3.4 Particle Confinement and Equilibrium . . . . 27

3.3.5 EBT Plasma Modes . . . . . . . . . . 29

3.3.6 Plasma Parameters and Measurements ..... 33

3.3.7 Other Microwave Heated Bumpy Tori . . . . . . 34

3.3 .8 EBT as a Reactor ........... . . . 36

4. TECHNOLOGICAL APPLICATION OF MICROWAVE HEATING ..... 37

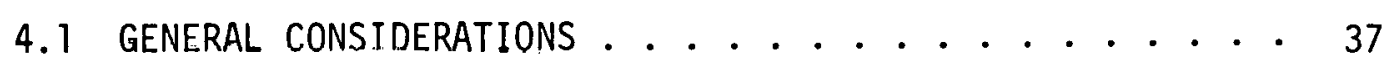

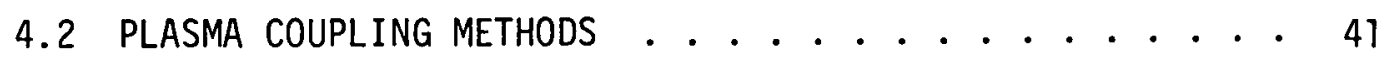

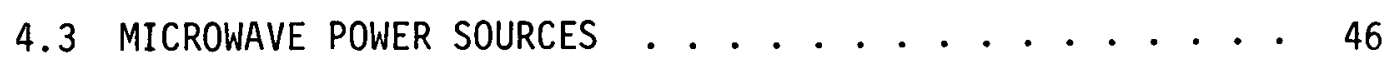

4.4 EBT-I MICROWAVE HEATING SYSTEMS . . . . . . . . 49

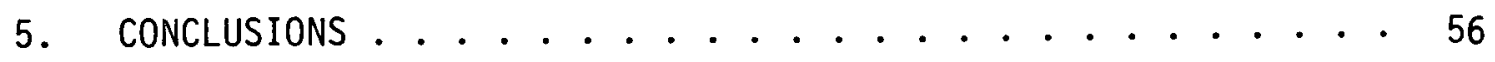

REFERENCES ............................ 57 


\section{THIS PAGE}

\section{WAS INTENTIONALLY LEFT BLANK}




\section{LIST OF FIGURES}

FIG. 1. Configuration of magnetic field in the ELMO Bumpy Torus. Two microwave frequencies $(10.6 \mathrm{GHz}$ and $18 \mathrm{GHz}$ ) are fed from the opening on the inside wall of the cavity. The wave mode at the injection port is "ordinary" rather than "extraordinary." The hot electron ring (runaway electrons) is observed to be a narrow belt encircling the local 2nd harmonic resonance (for $18 \mathrm{GHz}$ ) region in the midplane. The maximum microwave heating takes place at the cyclotron resonance zone (hatched in the figure). This makes it conveniently possible to control the density and temperature profiles in the bumpy torus and also analogously applicable to tokamak plasmas................

FIG. 2(a). CMA diagram for cold plasma. (1: electron-cyclotron resonance; 2: upper hybrid resonance; 3 : plasma frequency; 4: cyclotron cutoff.)

FIG. 2(b). CMA diagram for plasma in magnetic mirror or in bumpy torus (top view) in the high density case. Straight lines delineate the cavity wall and magnetic field lines are parallel to the page.

FIG. 2(c). CMA diagram for tokamak plasma (cross section). The magnetic field lines are normal to the sheet ......... 9

FIG. 3. Sketch of EBT .............. 21

FIG. 4. Absorption of ECH power in EBT ......... 23

FIG. 5. Location of $\frac{1}{2} W_{\perp}$ points vs toroidal magnetic field determined by an inner skimmer on S3 ........... 25

FIG. 6. Plasma parameters vs $w_{\perp} \ldots \ldots . \ldots . \ldots . \ldots$

FIG. 7. $\tau_{\mathrm{e}} \mathrm{vs}_{\mathrm{e}} \ldots \ldots \ldots \ldots \ldots \ldots \ldots$

FIG. 8. EBT microwave heating ............ 50

FIG. 9. EBT resunanl heating power source $-60 \mathrm{~kW} \mathrm{cW}$ at $18 \mathrm{GHz} \ldots \ldots$.................. 51

FIG. 10. EBT resonant heating. Typical $r f$ control, monitoring, and protection for each of 24 mirror regions . . . . . . . . . 54 
ELECTRON-CYCLOTRON HEATING OF TOROIDAL PLASMA WITH EMPHASIS

ON RESULTS FROM THE ELMO BUMPY TORUS (EBT)*

\author{
R. A. Dandl, ${ }^{\dagger}$ H. O. Eason, and H. Ikegami ${ }^{\ddagger}$ \\ Oak Ridge National Laboratory \\ Oak Ridge, Tennessee 37830 \\ United States of America
}

ABSTRACT

Microwave heating at the electron-cyclotron frequency has been effectively employed to heat plasmas confined in open and closed magnetic confinement geometry where the applied heating frequency was near or above the plasma frequency. The earliest experimental investigations demonstrated the effectiveness of plasma electron-cyclotron heating (ECH) and later theoretical work validated these observations. In this review, we briefly consider some of the more relevant ECH propagation processes and heating mechanisms. Results are presented from some of the more recent toroidal ECH experiments, including tokamaks, but principally from the ELMO Bumpy Torus (EBT). In the last section, we discuss the technological considerations so important to successful applications of ECH to plasma experiments.

\footnotetext{
* Research sponsored by the Office of Fusion Energy (ETM), U. S. Department of Energy under contract W-7405-eng-26 with the Union Carbide Corporation.

tRetired; Consultant at General Atomic, La Jolla, California. 中Consultant, Institute of Plasma Physic's, Nagoya University, Nagoya, Japan.
} 


\section{INTRODUCTION}

The two most commonly used methods for heating plasma electrons in toroidal geometry are ohmic heating and electron-cyclotron heating (ECH). Although ohmic heating is a convenient and efficient method of plasma heating when the plasma electron temperature is below about $2 \mathrm{keV}$, it becomes less effective at higher temperatures because the plasma resistivity is proportional to $\mathrm{T}_{\mathrm{e}}^{-3 / 2}$ and bremsstrahlung losses scale as $\mathrm{T}_{\mathrm{e}}^{1 / 2}$. The temperature saturation of ohmic heating makes auxiliary tokamak heating systems necessary.

A distinct advantage of microwave heating of electrons is the relative insensitivity of heating rate to the electron temperature. This results from the nature of the basic energy absorption process in $\mathrm{ECH}$, which is Doppler-shifted electron-cyclotron damping. However, in most ECH experiments, both the plasma density profiles and the magnetic confining field geometries are sufficiently nonuniform that such details as wave propagation, refraction, and mode conversion are important.

The earliest application of microwave heating of plasmas was the ECH experiments in simple magnetic mirrors [1-11], in which the applied frequency was near or above the plasma frequency. The microwave frequency was arranged to resonate with the electron gyrofrequency on constant-B (mod-B) surfaces chosen so that mirror-trapped electrons would be effectively heated. Later experiments also employed ECH in mirror quadrupole and multipole geometries [10-15]. More recently, the method has been adapted to toroidal geometry and has been used rather successfully to heat plasma in the ELMO Bumpy Torus (EBT) [16-17] and some Russian tokamaks [18-25]. 
The first experimental investigations of ECH phenomena in mirror machines considerabiy predated theoretical studies of the subject and were principally designed to emphasize the generation of so-called hot electron plasmas having kinetic electron temperatures ranging from 0.1 to $2 \mathrm{MeV}$.

Other possible applications of ECH are: control of the current profile of tokamak plasmas in connection with disruptive instabilities, control of $\beta$ poloidal independent of the plasma current, microwave discharge cleaning of confinement vessel surfaces, and preionization. Microwave discharge cleaning simply involves a low power continuous wave (cw) source operating at a fixed frequency set low enough that the toroidal magnetic field could be operated continuously and swept slowly in time so that the intersection of the $E C H$ resonant mod-B surface and liner wall would brush over the whole liner surface. Preionization using $E C H$ is a very obvious application of the spatially optional heating mod-B's which are possible with microwave heating.

2. GENERAL ELECTRON-CYCLOTRON PLASMA HEATING CONSIDERATIONS

\subsection{MICROWAVE COUPLING TO PLASMA}

The two dominant heating mechanisms involved in the microwave heating of plasmas are rather hard to separate. One is the collisionless damping of microwaves propagating at a frequency near the electroncyclotron frequency and the other is the linear conversion [26-31] of 
electromagnetic wave energy into longitudinal waves near the upper hybrid resonance. Cyclotron damping resul.ts from the resonant interaction between electromagnetic waves and electrons when the frequency is Doppler-shifted to the electron-cyclotron frequency. At cyclotron resonance, $\omega=\omega_{c e}$ (in the low density limit where $\left.\frac{\omega_{p}^{2}}{\omega_{c e}^{2}} \ll 1\right)$, the microwave power absorption coefficient for extraordinary waves is approximately given by [32]

$$
\alpha \cong \frac{f_{p}^{2}}{2 \pi f c}\left(\frac{m c^{2}}{T_{\rho}}\right)^{1 / 2}=6 \times 10^{-11} \frac{n}{f \sqrt{T_{e}}} \mathrm{~cm}^{-1},
$$

where $\mathrm{n}$ is in (centimeters) ${ }^{-3}, T_{e}$ in kiloelectron volts, and $f$ in gigahertz. For $n=10^{12} \mathrm{~cm}^{-3}, f=18 \mathrm{GHz}$, and $T_{e}=1 \mathrm{keV}$, the absorption length is $3 \mathrm{~mm}$. The microwave energy can be absorbed in a single pass through the plasma when the absorption length is comparable or even smaller than the scale length of the change in magnetic field as given by $\Delta H / H \sim \mathrm{kV}_{\mathrm{th}} / \omega$. For ordinary waves, $\alpha \simeq f_{p}^{2} / 2 \pi f c$, which is $\beta(\beta=v / c)$ times smaller than that given in Eq. (1).

Generally, the microwave power absorption as given by Litvak et al. [25] and Akhiezer et a1. [38] is:

$$
\frac{d w(r)}{d t} \simeq K\left(\omega_{p e}^{2}(r) / \omega^{2}, \theta\right) \exp \left[-\left(\frac{\omega-s \omega_{c e}(r)}{k_{11} v_{t h}(r)}\right)^{2}\right]
$$

where $\omega_{\text {pe }}(r)$ is the local, electron plasma frequency, $\omega_{c e}(r)$ is the 
electron-cyclotron frequency, $s=1,2,3, \ldots$ is the wave number parallel to the magnetic field, and $\theta$ is the angle between the direction of propagation and the magnetic field. For ordinary mode coupling, where the electric field is parallel to the magnetic field lines, the absorption rate is approximately $\beta$ times smaller than that given by Eq. (2). The power absorbed in the plasma can be obtained by integrating Eq. (2) along the ray path. For the limiting case where all of the power is dissipated in the plasma, the increase in plasma temperature is simply

$$
\delta T=P_{\tau_{E}} / n V,
$$

where $P$ is the total microwave power input, $\tau_{E}$ is the energy confinement time, $n$ is the plasma density, and $V$ is the volume of the plasma.

A typical ECH application, illustrated in Fig. 1, is the heating of plasma in a magnetic mirror. This is an equatorial plane cut showing the magnetic field geometry of one section of the ELMO Bumpy Torus. Mirroring collisionless electrons travel along flux lines (dashed lines) and pass through mod-B surfaces (solid lines). In the resonance region, the electrons gain energy from the microwave field through a stochastic process. Because the electrons are accelerated to gain perpendicular kinetic energy with respect to the magnetic field, they tend lo gather closer to the midplane of the mirror geometry. At electron-cyclotron resonance, where $n \equiv c k / \omega \rightarrow \infty$, the microwave field is not longitudinal [33]; however, it is longitudinal at the upper hybrid resonance. 


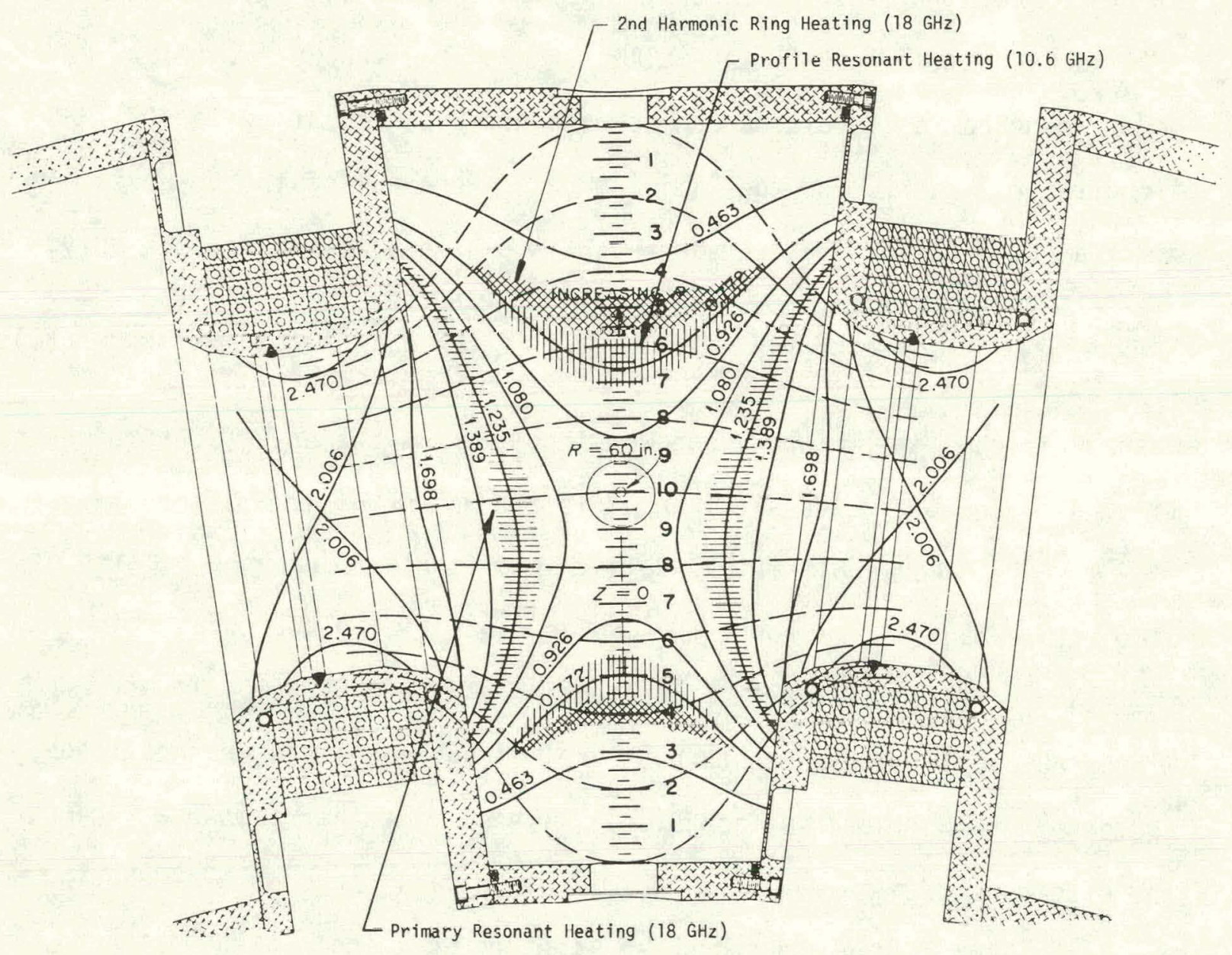

EBT Mod-B Contours (-), Flux I ines (---), and Heating Ceometry $(/ / 11),,($ ( $x \times x x)$

FIG. 1. Configuration of magnetic field in the ELMO Bumpy Torus. Two micrnwave frequencies $(10.6 \mathrm{GHz}$ and $18 \mathrm{GHz})$ are fed from the upening on the inside wall of the cavity. The wave mode at the injection port is "ordinary" rather than "extraordinary." The hot elcctron ring (runaway electrons) is observed to be a narrow belt encircling the local 2nd harmonic resonance (for $18 \mathrm{GHz}$ ) region in the midplane. The maximum microwave heating takes place at the cyclotron resonance zone (hatched in the figure). This makes it conveniently possible to control the density and temperature profiles in the bumpy torus and also analogously applicable to tokamak plasmas. 
Microwave heating by linear conversion [26-31] of electromagnetic wave energy into longitudinal waves takes place near the upper hybrid resonance and is similar to lower hybrid wave heating $[26,28-29,34-36]$. The resonance region in a plasma is almost always accompanied by an evanescent region so that, in coupling to an inhomogeneous plasma, the wave must penetrate the evanescent region into the resonance region. Access can be gained to the tokamak plasma resonance region, where the microwave heating power is transformed into longitudinal plasma waves, by launching the microwave power from the high magnetic field side of the torus (that is, from the inside wall region).

The usual extraordinary mode cold plasma dispersion relationship has a resonance branch at $\omega_{U H}=\sqrt{\omega_{p e}^{2}+\omega_{c e}^{2}}$, which is the well-known upper hybrid resonance. The cold plasma approximation, however, breaks down at resonance when $k \rightarrow \infty$, or $\mathrm{kV}_{\mathrm{th}} / \omega \rightarrow \infty$, but the resonance branch develops continuously into the thermal plasma wave branch when thermal effects are taken into consideration. These plasma waves are not damped if the wave vector is strictly perpendicular to the magnetic field. Usually, however, some component of the wave vector is parallel to the magnetic field and the waves do dissipate their energy in the plasma by cyclotron damping where the condition $\omega=s \omega_{c e}-k_{\| l} v_{t h}$ is satisfied. Thus, after the microwave radiation has been transformed into longitudinal waves near the upper hybrid resonance, these waves will propagate to the region of the cyclotron resonant surface where the energy will be absorbed by the plasma electrons. After mode conversion, Landau damping can also provide an important process for the dissipation of longitudinal waves (for $s=0$ ). 
The CMA diagram [37], which facilitates the discussion of the propagation of microwaves in a plasma, is shown in Fig. 2(a). In simple mirror machines or in a vacuum bumpy torus; the magnetic field radially increases from the wall towards the plasma center except in the region of the mirror throat, so that propagation of the extraordinary wave requires transmission through the cyclotron cutoff region before it reaches the upper hybrid resonance region as a plasma wave, Fig. 2(b). Thus, this type of coupling is generally very inefficient. Since this cutoff region is almost a ways locatcd outside the cyclotron resonance reglon, wive energy usually ends up being dissipated in the plasma periphery. The preferred tokamak plasma heating scheme, as indicated in Fig. 2(c) of the CMA diagram, employs upper hybrid resonance via linear conversion of microwave radiation launched from the inside wall where both conditions $\omega_{\mathrm{ce}} / \omega>1$ and $\omega_{\mathrm{pe}} / \omega<1$ are satisfied.

When the plasma is transparent to ordinary waves $\left(\omega>\omega_{p \theta}\right)$, it has been often demonstrated experimentaliy that effective ECH coupling results from radially introducing microwaves in the dominantly ordinary wave mode, by means of a waveguide simply flanged to the metal wall of the plasma vacuum vessel, although more power efficient matching circuits are to be preferred (see Seclion 4.2). The microwave radiation into such cavity coupled plasmas is usually a mixture of both ordfllary and extraordinary modes. For example, in EBT-I, the microwave feed is through 24 openings, each consisting of two ports from a hybrid coupler. The electric field at the port openings is arranged to be parallel to the magnetic field, thereby emphasizing the ordinary wave mode coupling. 


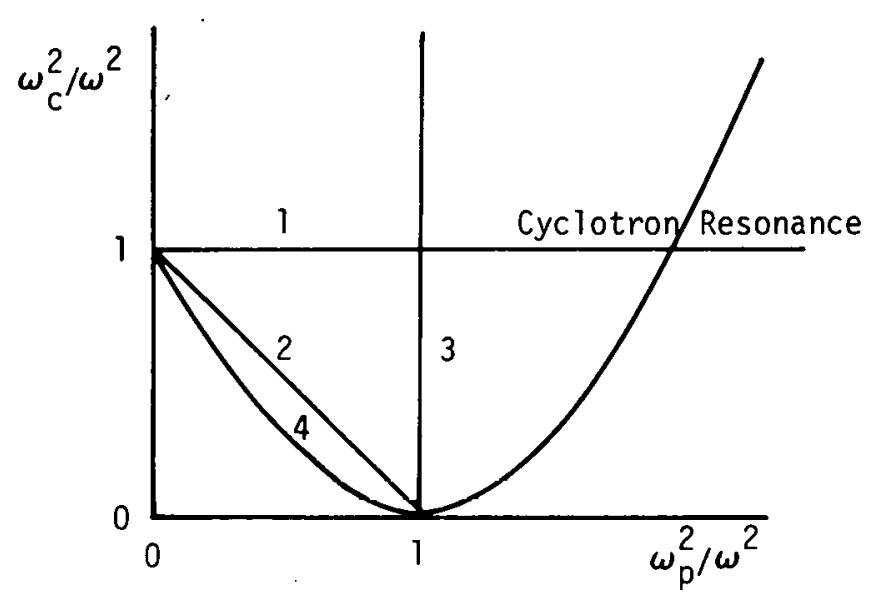

FIG. 2(a). CMA diagram for cold plasma. (1: electron-cyclotron resonance; 2: upper hybrid resonance; 3: plasma frequency; 4: cyclotron cutoff.)

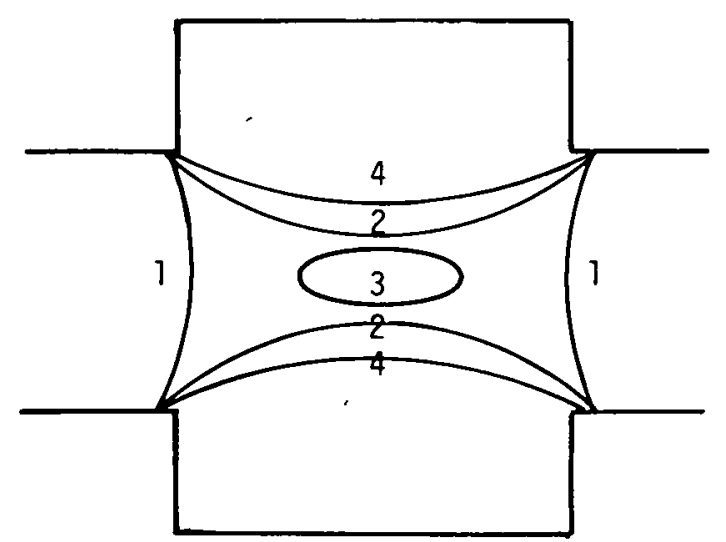

FIG. 2(b). CMA diagram for plasma in magnetic mirror or in bumpy torus (top view) in the high density case. Straight lines delineate the cavity wall and magnetic field lines are parallel to the page.

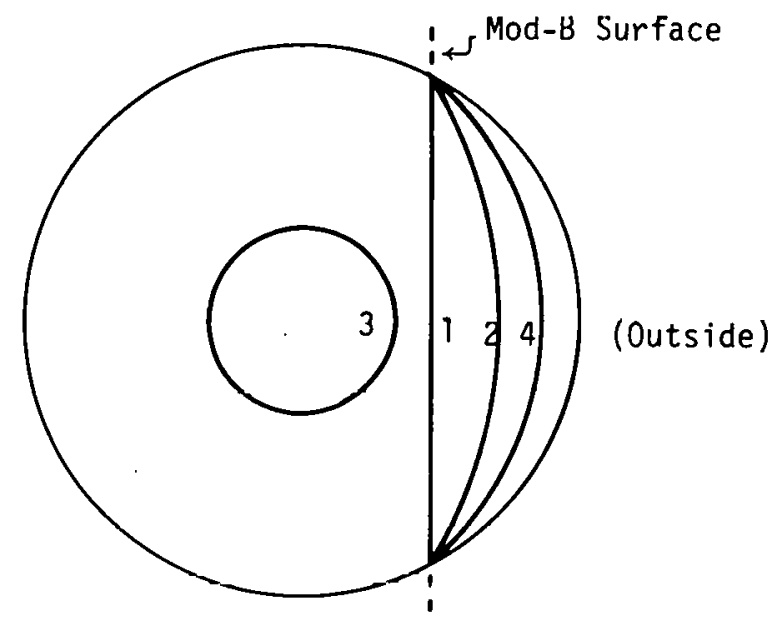

FIG. $2(c)$. CMA diagram for tokamak plasma (cruss secliun). The maynelic field lines are normal to the sheet. 
In tokamak experiments [19-25], the interaction between the ordinary wave and the plasma has been observed to be an order of magnitude or ( $\beta \cong V_{t h} / c$ ) smaller than that for the extraordinary wave coupling. It has been reported [25] that ordinary wave power absorption is much smaller than that of the extraordinary wave when the power injected into the tokamak is in the direction of increasing magnetic field; i.e., from the outside of the tokamak, with less than a $60^{\circ}$ angle between the wave vector and the magnetic field at the plasma boundary. However, for injection angles of $65^{\circ}$ to $80^{\circ}$, it is estimated that absorption is of the same order for both types of waves. As alluded to earlier, however, ordinary mode microwaves launched perpendicular to the surface of a fairly dense plasma can be absorbed almost as efficiently as extraordinary waves because refraction and reflection of multitransits can effectively alter polarization to again permit plasma heating by cyclotron damping. Alikaev et a1. [24] conclude that when the wave vector is at $60^{\circ}$ to the magnetic field, the damping for extraordinary waves is so large that their energy will be almost entirely dissipated in heating the periphery of toroidal plasmas, while the energy of the ordinary waves goes mainly into bulk heating. As the electron temperature is increased, it is necessary to launch the wave at larger angles to avoid shifting the heating region toward the plasma surface. It is worth emphasizing that the evanescent layer difficulties with the extranrdinary wave launch can be avoided by employing the previously mentioned ordinary wave launch. So that it can be argued that whatever illumination scheme is employed the dominant process for 
converting microwave energy into plasma heat is the mechanism of cyclotron

damping; i.e., the wave energy in both the ordinary mode and the extraordinary mode is ultimately deposited in the region of fundamental or harmonic cyclotron resonances, and the amount of increase in the plasma energy is simply given by Eq. (3).

\subsection{ELECTRON-CYCLOTRON HEATING RATE}

Although the earliest ECH experiments were accompanied by primitive attempts at quantitative description of the heating processes, it was considerably later before even idealized calculations gave insight to the rather intricate nonlinear problem of the interaction of spatialiy complex electromagnetic fields and anisotropic damping media.

In the subsequent theoretical studies of these plasmas [39-47], electromagnetic propagation into the plasma from a single frequency source was assumed and the main efforts were directed to computing the electron heating rate by the applied time-varying electric fields. Because the time-varying electric field is usually at a single frequency, and because the confining fields were magnetic mirrors, the theories were concerned with the randomizing processes that caused heating. In this stochastic heating process, the electrons interact with the oscillating electric field $E$ for a time $\Delta t$ during each bounce interval $\tau_{b}$ between the mirrors. The heating rate was estimated to be

$$
R=\frac{\Delta W}{\Delta t} \simeq \frac{1}{2} m\left(\frac{e E}{m} \Delta t\right)^{2} \tau_{b}^{-1},
$$

where $W$ is the electron kinetic energy. This is a general form of the heating rate for trapped electrons in a nonuniform magnetic field. The 
bounce time $\tau_{b}$ may be a circulating time in a toroidal configuration, and the interaction time $\Delta t$ depends on the nonuniformity [39].

Thus, in mirror machines and in the bumpy torus, electrons resonantly interacting with the microwave field ga in perpendicular energy, thus changing their reflection points in the magnetic mirror field after every pass through the local cyclotron resonance zone. Stochastic acceleration of particles does not necessarily require turbulent electric fields with a wide frequency spectrum. Periodic nonrandom forces can lead to stochastic acceleration, two typical examples of which are rermi acceleration [48] and $\mathrm{ECH}$ in a magnetic mirror field. Randomness in phase between the electron and the microwave fields can be introduced in each successive interaction by processes such as nonadiabatic drifts across the magnetic field or by an equivalent broadening of the $w$ spectrum such as a diffused $K$ spectrum in the actual system sampled by the electrons.

It is rather commonly obscrved that a small fractinn of particles r.an be accelerated to high energy by stochastic heating. For ECH in magnetic mirror geometry, it is generally assumed that electruns only gain energy perpendicular to the external magnetic field. If the change in the energy $\Delta W$ in an interval of time $\Delta t$ is such that $\langle\Delta W\rangle$ and $\left\langle\Delta W^{2}\right\rangle$ contain terms linear in $\Delta t$ and all higher products have expectation values varying as higher powers of $\Delta t$, then the time evolution of the distribution function can be described by the Fokker-Planck equation [49] to give a qualitative picture of the stochastic heating of energetic electrons by microwave fields in the aforementioned geometry

$$
\frac{\partial f}{\partial t}=-\frac{\partial}{\partial W}\left(\left\langle\frac{\Delta W}{\Delta t}\right\rangle f\right)+\frac{1}{2} \frac{\partial^{2}}{\partial W^{2}}\left(\left\langle\frac{\Delta W^{2}}{\Delta t}\right\rangle f\right),
$$


where $f(t, W)$ is the time-dependent energy distribution function. By using the relations

$$
\langle\Delta W / \Delta t\rangle=R \quad \text { and } \quad\left\langle\Delta W^{2} / \Delta t\right\rangle=2 W R,
$$

we can rewrite the equation by introducing both loss term and cold plasma source term, Q, as

$$
\frac{\partial f}{\partial t}=R \frac{\partial}{\partial W}\left(W \frac{\partial f}{\partial W}\right)-\frac{f}{\tau(W)}+Q \delta(W),
$$

whose stationary solution is obtained with a constant heating rate, $R$, and decay time, $\tau$, as

$$
f(\infty, W)=\frac{2 Q}{R} K_{0}(\sqrt{4 W / R \tau}),
$$

where $K_{0}(z)$ is the modified Bessel function of the second order. From this equation, the average kinetic energy of the electron is given by

$$
\langle W\rangle=\left\{\begin{array}{lll}
\frac{Q t}{n_{e o}} R \tau & \text { for } & t \ll \tau, \\
R \tau & \text { for } & t \gg \tau,
\end{array}\right.
$$

where $n_{e o}$ is the initial density of the cold electron source.

In accordance with this stochastic heating model, the heating rate was determined experimentally [50] by measuring the time-dependent energy distribution function of energetic electrons generated by $\mathrm{ECH}$ in a simple mirror machine. The heating rate for a microwave field of 30 $\mathrm{V} / \mathrm{cm}$ was determined to be $10 \mathrm{MeV} / \mathrm{sec}$, which is quite common $[11,51]$ in most of the ECH experiments in mirror machines for the case where $\omega>\omega_{\text {pe }}$. 
Whether ECH results only in the generation of energetic electrons or in heating of the plasma as a whole, the final electron temperature is determined by a combination of three parameters: heating rate, confinement time, and plasma energy transfer rate. In relatively low density plasmas, common in ECH mirror experiments, the heating rate is relatively large and the particle confinement time for energetic electrons is shorter than the time for energy transfer between electrons, so that the plasma is usually composed of both a hot and cold electron distribution. In steady state, the hot electron temperature (average kinetic energy) is determined by Eq. (9). For $R=10^{7} \mathrm{eV} / \mathrm{sec}$ and $\tau=10$ msec, we find $\langle W\rangle=100 \mathrm{keV}$. Although one would expect the'plasma to be heated as a whole to the energy $\langle W\rangle \simeq R \tau_{e}$ when the confinement time is longer than the collisional energy transfer time, $\tau_{e}$, the bulk of the microwave power is dissipated in cold plasma throughput and, depending on the heating configuration, in enhanced mirror losses via microinstabilities.

\subsection{MICROWAVE HOT ELECTRON PLASMA INSTABILITIES}

A significant effect of high ECH rates is the production of anisotropic electron distributions which result in anisotropy-driven microinstabilities. Several microinstabilities ['9,52-54] driven by anisotropic electron distributions caused by high heating rates have been observed in microwave-heated magnetic mirror devices. Since these instabilities usually result in a rapid pitch angle flips into the loss cone, they may cause little or no increase in plasma losses in toroldal devices. Also, in some tokamak experiments [56], electron-cyclotron 
heating has generated runaway electrons at low plasma densities, causing an instability which increased the plasma column transverse energy. This increased. transverse energy was accompanied by a decrease in longitudinal energy of the runaway electrons and was rapidly lost to the walt.

Some other instabilities, of concern, which derive their energy source from the anisotropic energy distributions possible in mirrorconfined ECH plasmas are curvature drift instabilities [56] and the cyclotron instability [57]. The curvature drift instability can be stabilized by cold electrons if their population is above a certain critical density. This stability condition is rather easily satisfied in high beta, hot electron plasmas which can produce a minimum-B (min-B) field self-consistently and which also can have a large inherent drift frequency, $k v_{D} \gg \omega_{c i}$, resulting from very high electron temperatures.

The cyclotron or Whistler instability [57] has a characteristic frequency at $\omega \lesssim \omega_{c e}\left(\tau-T_{\|} / T_{\perp}\right)$, where $T_{\|}$and $T_{\perp}$ are the parallel and perpendicular electron temperature relative to the magnetic field. This instability is also stabilized by the presence of a cold-electron component which has an isutropic temperature. This instability was artificially excited by radiating a short microwave pulse into the plasma and then observed by scanning across magnetic field lines with an antenna sensitive to circularly polarized electromagnetic waves [54]. The instability was observed to drive the hot electrons into the mirror loss cone within a few microseconds. 


\section{MICROWAVE HEATING EXPERIMENTS}

\subsection{MICROWAVE HEATING IN MAGNETIC MIRROR GEOMETRY}

Experimental results from plasmas generated by $\mathrm{ECH}$ in both simple and min-B mirror machines have been extensively reported in the past and therefore are not discussed in detail here. These plasmas are characterized by rather low density and cold ions. Because of the low density, the collisional energy transfer time is longer than the confinement time, so that ECH in magnetic mirrors usually results in the generation of energetic electrons with an average kinetic energy of several hundred kiloelectron volts or more. The plasma beta can be on the order of $50 \%$ so the electrons can be internally stabilized against flutes by their self-generated min-B configuration as long as the surface is stabilized by cold plasma $[56,58]$. Because these energetic electrons are highly anisotropic in velocity space, they are trapped in the midplane of the magnetic mirrors and form very high beta plasma rings $[6,7]$. Furthermore, this ring-shaped structure encompasses the constant mod-B surface at $\omega=2 \omega_{c e}[8-10,16-17]$. This shel1 structure is a peculiar but common feature of microwave-produced hot electron plasmas in simple mirror traps, where the microwave field is strongly coupled to harmonics of the relativistic electrons. The EBT concept employs such high $\beta$ rings for macroscopic stabilization.

It has also been experimentally observed [53] that the application of microwave power at frequencies above and below $\omega_{c e}$ can have useful plasma heating effects. In the lower frequency case, $\omega<\omega_{c e}$, the 
electrons primarily gain $V_{\|}$(relative to the magnetic field), and in the higher frequency case they gain $V_{\perp}$. Such heating considerations can provide control of the electron pitch angle distributions in some confinement configurations.

\subsection{RECENT MICROWAVE HEATING RESULTS IN TOKAMAKS}

Microwave heating of tokamak plasmas has been studied in several of the smaller Soviet tokamaks, notably Tuman-2 $[28,60]$, TM-3 $[19-20,23,28,61]$, and FT-1 [59]. Figure 2(c) illustrates the available ECH geometries accessible in tokamaks. In a smooth low $\beta$ torus, the mod-B. surfaces are cylindrical and concentric with the major torus axis. The result of heating on a particular mod-B surface is also shown in Fig. $2(\mathrm{c})$, where the intersection of this surface with the poloidal motion of the plasma can result in either shell or volume heating as a matter of choice. Because ECH could be used in tokamaks to change the conductivity of the outer shell of the plasma, a short, high power ECH pulse might be used to modify the initial current profiles to control the spatial distribution of the poloidal field and thereby raise the $\beta$ threshold for some instabilities.

It is interesting to compare the results of these two tokamak experiments. In Tuman-2, the plasma parameters are $R=40 \mathrm{~cm}, a=10$ $\mathrm{cm}, \mathrm{B}=2-5 \mathrm{kG}, \mathrm{n}=5 \times 10^{11}-3 \times 10^{13} \mathrm{~cm}^{-3}$, and $\mathrm{T}_{\mathrm{e}}=3-30 \mathrm{eV}$, where $\mathrm{R}$ and $a$ are the major and minor radius of the toroidal plasma, respectively. The plasma is heated by a 9-GHz microwave pulse of $300-\mu s e c$ duration at $50 \mathrm{~kW}$. It is reasoned that the linear transformation of microwaves into slow plasma. waves at the upper hybrid resonance is the heating mechanism. 
In TM-3, the plasma parameters are $R=40 \mathrm{~cm}, a=8 \mathrm{~cm}, B=5-25$ $k G, n=3-10 \times 10^{12} \mathrm{~cm}^{-3}$, and $T_{e}=200-400 \mathrm{eV}$. Microwave heating is effected by a $50-\mathrm{kW}$ pulse at $30 \mathrm{GHz}$ of $500-\mu \mathrm{sec}$ duration. Power is injected into the plasma through a window in the chamber directly connected to a circular waveguide of $3-\mathrm{cm}$ diameter. The level of reflected power throughout the entire range of discharge conditions is reported not to exceed $10 \%$ of the introduced power. According to Golant [28], effective absorption of the microwave energy was observed at the upper hybrid resonance; however, at higher electron temperatures, more effective heating was observed at $\omega=\omega_{c e}$ and $(1)=2 \omega_{c e}$. According to Alikaev [61], the heating in TM-3 resulted in electron temperature increases of as much as $150 \mathrm{eV}$ and in a $\beta_{\mathrm{p}}$ of $\cong 2.2$. He claims, however, that al though heating is observed at $\omega \simeq \omega_{C}$ no evidence of heating was observed at the upper hybrid resonance. It was also reported that at $\omega \simeq 2 \omega_{c}$, the microwave power is mainly absorbed by runaway electrons with no lon heatiny. Golant ascribes the heating mechanism to the linear transformation of electromagnetic waves into slow longitudinal waves at the upper hybrid resonance region. Alikaev, on the other hand, asserts the heating to be simply due to linear cyclotron damping at $\omega=s \omega_{c e}$, i.e., conventional electron-cyclotron heating. The difference in interpretation is probably due to the difference in electron temperatures. At relalively low tem peratures (in the experiments on Tuman-2) direct cyclotron absorption is weak for one wave transit and the probable dominant process is the absorption of a longitudinal wave resulting from a transformation in the vicinity of the upper hybrid resonance. At higher temperatures (as is typical of 
most TM-3 experiments) cyclotron absorption is large in one pass of an extraordinary wave, accounting for the observed heating.

In any event, electron-cyclotron heating generally resulted in an increase in electron temperature and was observed to lead to an increase in the conductivity of the plasma, resulting also in an increase in current when ohmic heating voltage was kept constant $[28,60]$. For constant current, the observed increase in voltage on the circumference of the plasma column was interpreted to be due to the displacement of the plasma column. The increase of the diamagnetic signal upon application of ECH is interpreted to be due both to an increase in electron temperature and also to a slight increase in plasma density [60-61].

The most desired result from ECH experiments would be for the microwave power to be absorbed by the bulk plasma rather than a small group of runaway electrons, accompanied also by an increase in energy confinement time with increasing electron temperature, perhaps realizing $B_{p} \simeq 2.2$ without major instabilities or a loss of plasma equilibrium [61].

These measurements of diamagnetism and plasma conductivity have made it possible to estimate the effectiveness of tokamak ECH. For optimum conditions, the ratio of the microwave power deposited in the bulk plasma to the microwave output reaches $50 \%$. The power loss is considered to be due either to the dissipation of the wave energy in the plasma periphery where the energy confinement time is shorter, or to the attenuation of the wave in the opaque region. 
Electron-cyclotron heating of tokamak plasmas to date indicates the attractiveness of using high power microwaves in these plasma devices. It should be noted, however, that the experiments have only been conducted in small-scale devices, Tike Tuman-2 and TM-3, with comparatively short energy confinement times.

\subsection{MICROWAVE HEATING IN THE ELMO BUMPY TORUS}

\subsubsection{The ELMO Bumpy Torus (EBT) Experiment}

The ELMO Bumpy Torus, which is sketched in Fig. 3, is somewhat unusual in that the plasma is produced, heated, and stabilized by electron-cyclotron heating at microwave frequencies of $18 \mathrm{GHz}$ and 10.6 GHz [cf. Fig. 2(b)]. It has been known for more than twenty years [62, 65] that a plasma can be confined in a periodic, spatially modulated, toroidal magnetic field, the so-called bumpy torus. However, this configuration has received very 7 imited attention, primarily because of anticipated MHD instabilities [62].

The ELMO Bumpy Torus (EBT) consists of 24 connected inirrors with a $2: 1$ mirror ratio. The major radius is $150 \mathrm{~cm}$ and the minor radius at the mirror midplane is $25 \mathrm{~cm}$.

The following are typical EBT machine parameters.

\begin{tabular}{|c|c|}
\hline Magnetic field (maximum) & $5 \mathrm{kG}$ (midplane)-10 kG (mirror) \\
\hline Mágnetic ficld jower & $6 \mathrm{MW}$ \\
\hline Plasma volume & $\simeq 500$ liters \\
\hline Major radius & $150 \mathrm{~cm}$ \\
\hline Average aspert ratio & $10: 1$ \\
\hline Microwave power sources & $\begin{array}{l}60 \mathrm{~kW} \mathrm{CW} \text { maximum at } 18 \mathrm{GHz} \\
30 \mathrm{~kW} \mathrm{CW} \text { maximum at } 10.6 \mathrm{GHz}\end{array}$ \\
\hline
\end{tabular}




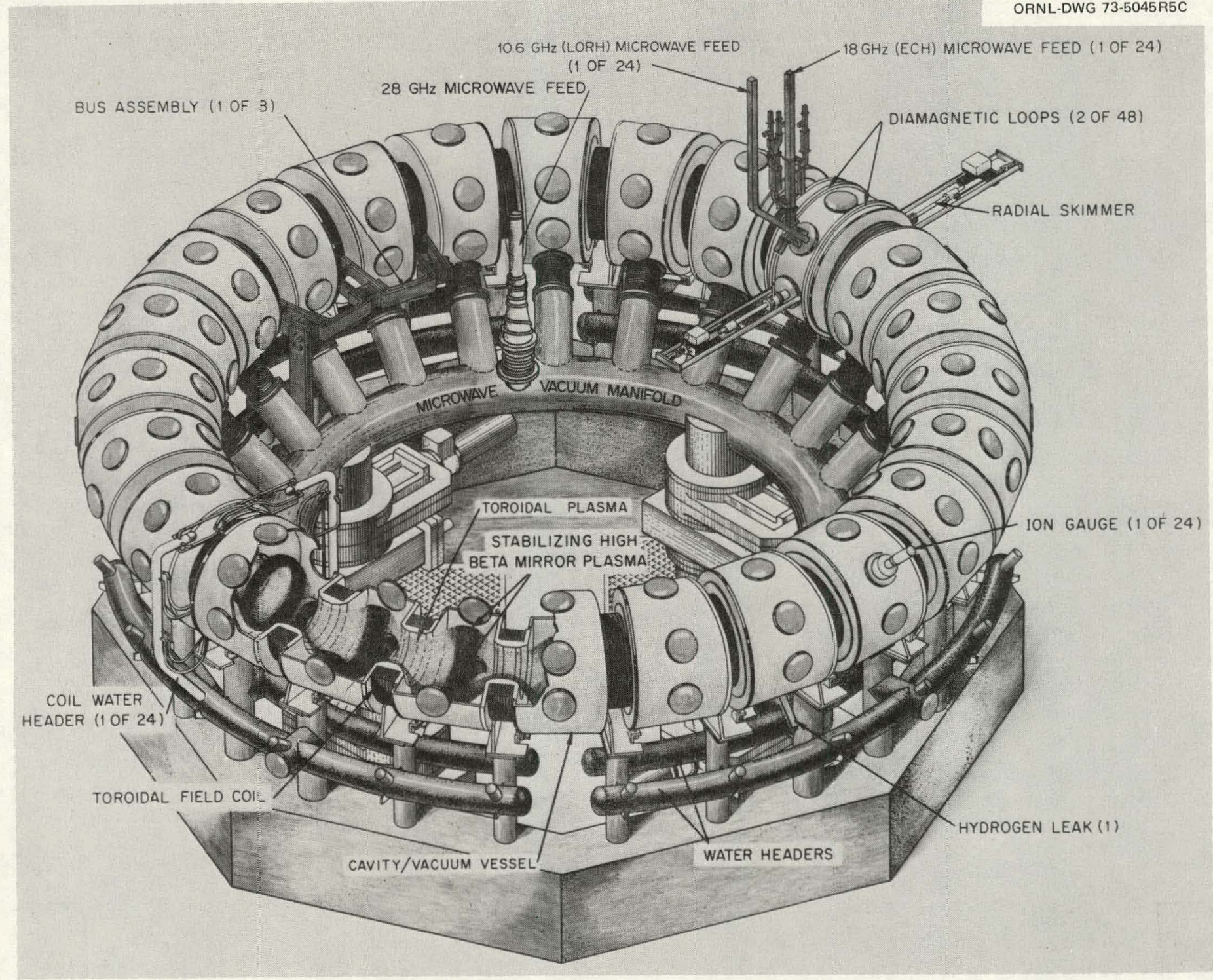

FIG. 3. Sketch of EBT. 
The EBT experiment is designed to circumvent the MHD instability problem by using the high $\beta$ properties of hot electron plasmas observed in the microwave-heated, open-ended magnetic mirror experiments throughout the preceding decade $[1-5,16-17,63-64]$. Experiments carried out in EBT-I [16-17] during the past five years have demonstrated the effectiveness of ECH in toroidal geometry and have supported the validity of the basic EBT premise: that plasma currents produced by the high $\beta$, hot electron annuli could provide a plasma equilibrium in a bumpy torus.

\subsubsection{Electron-Cyclotron Heating in EBT}

Microwave heating in EBT is concentrated on the electron-cyclotron resonant surfaces. Microwave power is coupled to the plasma in the ordinary wave mode from the opening of the hybrid coupler at the midplane of the inside-wall of each cavity. As is apparent from Fig. 2(b), the cyclotron resonance surface in EBT is well separated from the extraordinary mode by the cyclotron cutoff. Because of the corrugated nature of the toroidal field and the consequent field nonuniformity, plasmas are generated at the fundamental resonance surface and the second harmonic cyclotron resonance is mainly responsible for the generation of the energetic electrons resulting in the high $\beta$ annuli, which is also called the hot electron ring.

In a number of $\mathrm{ECH}$ experiments, we have observed the microwave power illuminating the plasma to be absorbed with an efficiency approaching $100 \%$. One such measurement of ECH coupling efficiency has been made in EBT using identical microwave launch and measurement circuits. The power attenuation factors in Fig. 4 are for the coupled power outputs of cavity N3, in which the power is launched, and two other mirror cavities, E4 and S4; five and 


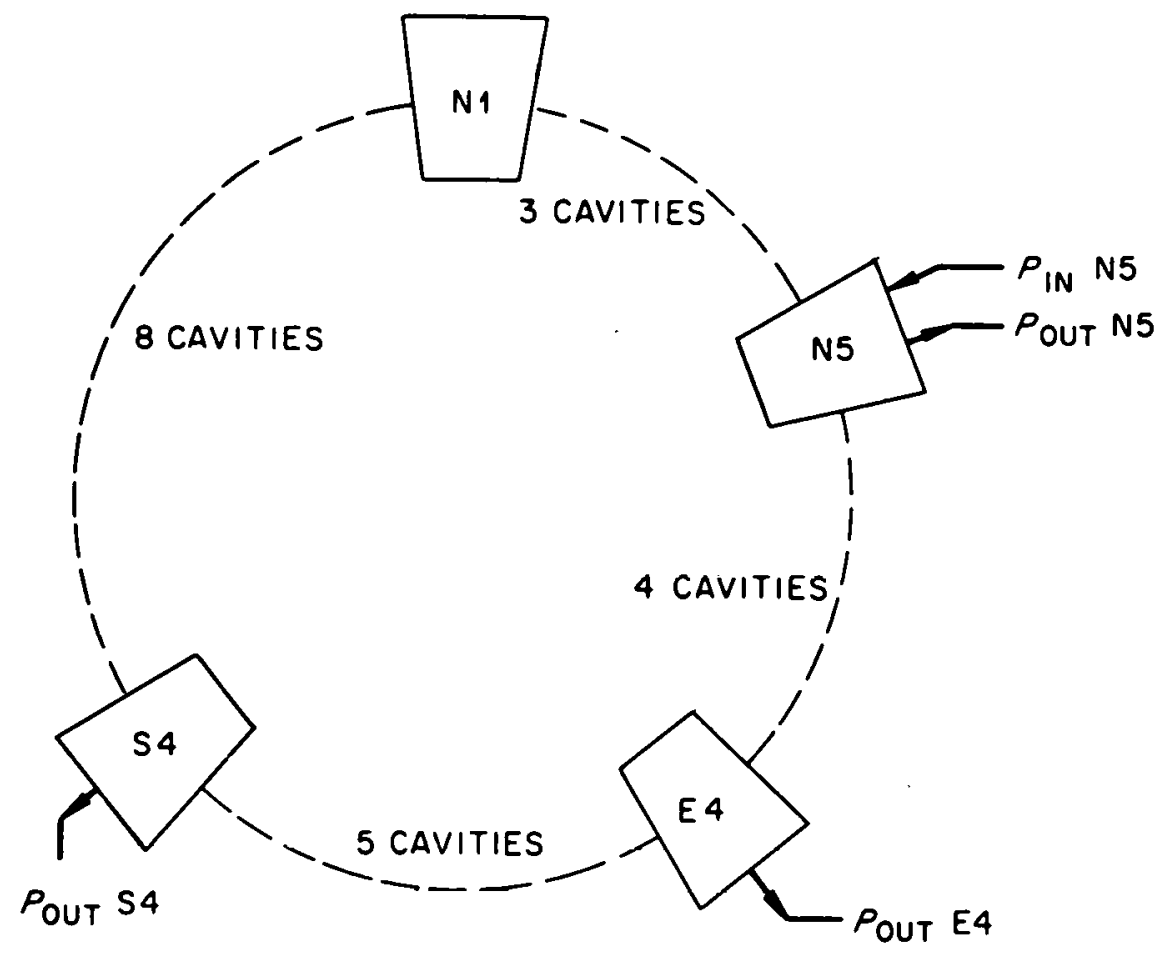

Power Source

$$
\frac{P_{\text {OUT }} N 5}{P_{\text {IN }} N 5} \quad \frac{P_{\text {OUT }} \text { E4 }}{P_{\text {OUT }} \text { N5 }} \quad \frac{P_{\text {OUT }} \text { S4 }}{P_{\text {OUT }} \text { N5 }}
$$

$18 \mathrm{GHz}$ ECH

$$
\begin{array}{lccc}
\text { Without Plasma } & 5 \times 10^{-3} & 0.2 & 0.4 \\
\text { With Plasma } & 1 \times 10^{-4} & 7 \times 10^{-4} & 7 \times 10^{-4}
\end{array}
$$

Microwave Attenuation

by Plasma in Cavity:

N5

E4

\$4

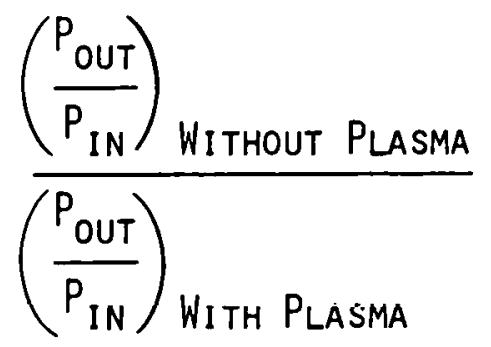

50

FIG. 4. Absorption of ECH power in EBT. 
nine cavities were removed respectively from the launch cavity. The presence of plasma reduces the power out of $\mathrm{N} 5$ by a factor of 50 and reduces the power out of E4 and S4 each by about a factor of $10^{4}$, showing the extremely high absorptivity in the electron-cyclotron resonant plasma. Incidentally, similar. measurements employing power sources whose microwave frequency $(55 \mathrm{GHz}$ ) was greater than the electron-cyclotron frequency everywhere in the volume showed very little attenuation by the cold plasma.

In contrast to bulk heating, experimental data showing the highly localized second harmonic coupling to the high $\beta$ ring electrons are illustrated in Fig. 5. As the magnetic field current is increased, the second harmonic resonance (with the bulk 18-GHz heating frequency) is observed to move radially outward as shown by the measured field values on the solid curve. The horizontal dashes are the experimentally determined positions of the annuli for each field value. These data, taken by drift surface limiting skimmer probes and diamagnetic flux integrators, are in good agreement with the second harmonic heating premise.

\subsubsection{MHD Stability}

Stability of the toroidal plasma component in EBT depends on the diamagnetism of the hot electron annulus which transforms part of the bumpy torus volume into an average min-B configuration. The toroidal core would otherwise be subject to simple interchange modes, shown by Kadomtsev [65] to be unstable in a scalar pressure closed-line torus with monotonically increasing $\int d \ell / B$. However, theory predicts that a hot electron component with $\beta$ in excess of about $7 \%$ should reverse the 


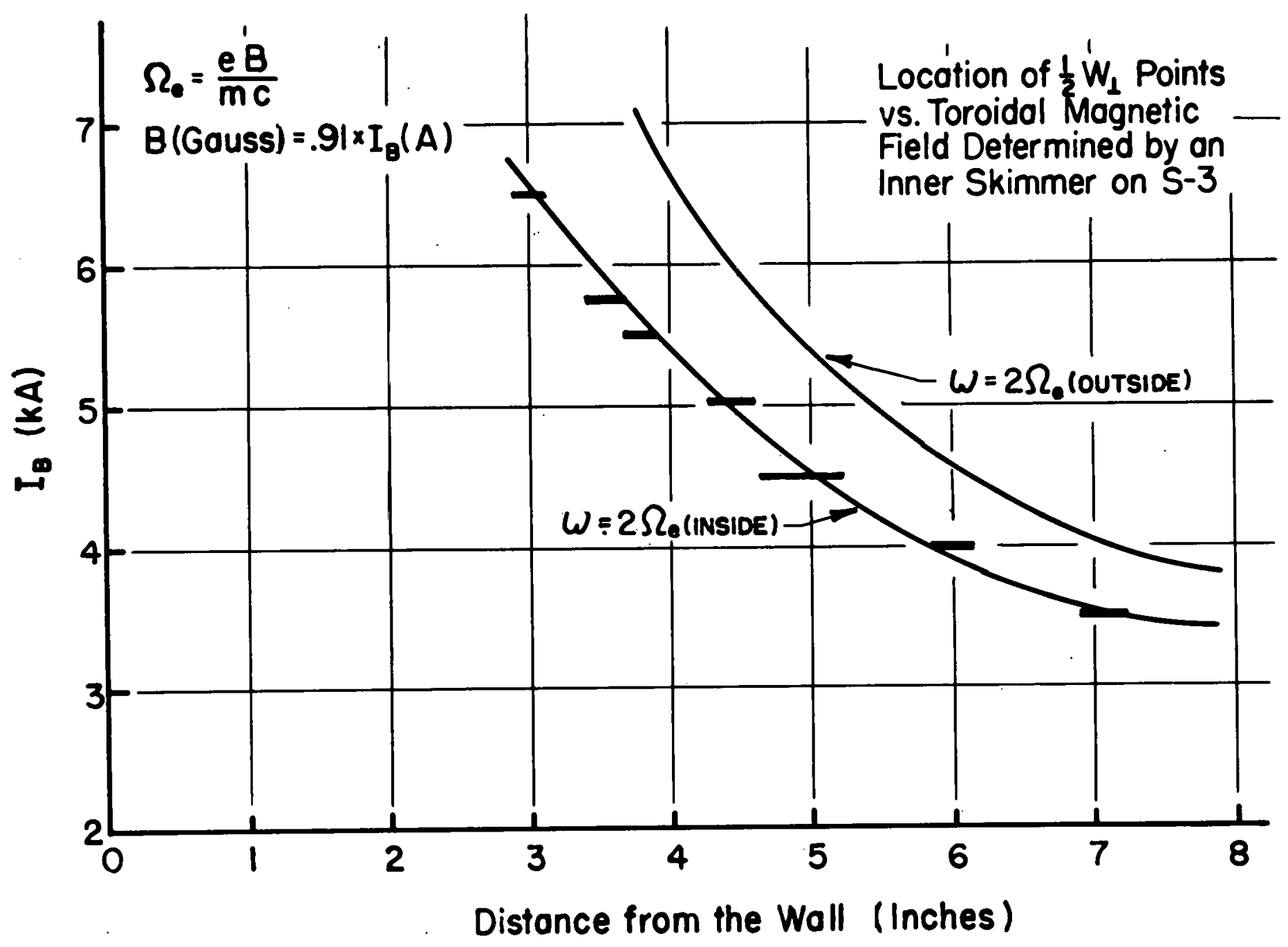

FIG. 5. Location of $\frac{1}{2} W_{\perp}$ points vs toroidal magnetic

field determined by an inner skimmer on S3. 
local gradient in the magnetic field intensity, thus satisfying Kadomtsev's criterion for stability. Furthermore, there is now experimental evidence to suggest that a critical value of $\beta$ in the annulus (on the order of $7 \%$ ) separates quiet from fluctuating modes of operation, which will be discussed later.

In normal EBT operation, the $\beta$ of the hot electron annuli can be sufficiently high (20-40\%) that another class of macroscopic instabilities, like pressure-driven ballooning modes, becomes energetically possible. The stability criterion for a bumpy cylinder may be given by [66]

$$
\left\langle\frac{\kappa}{r B} \frac{\partial p_{\| l}}{\partial \psi}+\frac{\partial \ln B}{\partial \psi} \frac{\partial p_{1}}{\partial \psi}\right\rangle+\left\langle\frac{\partial p_{\perp}}{\partial \psi}\right\rangle^{2} /\left\langle\tau^{2}\right\rangle \leq 0,
$$

which is roughly equivalent to the condition satisfied by the hot electron annul $i$ in order that it reverse the radial magnetic field gradient. This criterion has a number of rather general implications for stability of the annuli.

In Eq. (10), the $\oint \mathrm{d} l / \mathrm{B}$ average is denoted by $\langle\ldots\rangle$, where $\psi$ is a flux function, the field curvature is

$$
\vec{\kappa}=\frac{1}{B} \vec{\nabla}_{\perp} B+\frac{(\vec{\nabla} \times \vec{B}) \times \vec{B}}{B^{2}},
$$

and the mirror stability criterion is $\tau>0$, where

$$
\tau=1+\frac{1}{B} \frac{\partial p_{1}}{\partial B} \quad .
$$


Guiding center analysis would suggest that the most important macroscopic modes are the pressure-driven ballooning modes; however, this theory is not applicable to the hot electron annuli in which the electron Larmor radii are large and drift frequencies exceed the ioncyclotron frequency. A more correct, but geometrically simplified, Vlasov analysis showed that the annuli are stabilized by the high drift frequency of the electrons [56].

Guiding center and MHD analyses do apply to the toroidal core because the lower temperature components have much smaller gyroradii. Preliminary results demonstrate that the toroidal $B$ in the present experiment is not limited by instabilities. The germane stability analysis suggests that the $\beta$ in the toroidal core can be comparable to the $\beta$ in the annuli and the toroidal plasma still be stable within the MHD framework.

\subsubsection{Particle Confinement and Equilibrium}

Although a bumpy torus magnetic field produced by line currents provides absolute confinement of single particles [67], such a field must practically be produced by coils with finite current densities outside vacuum walls, so that the guiding center drift motion then leads some particles directly to the chamber walls. Even in the ideal case, some particles have crescent-shaped drift orbits which do close within the vacuum chamber, but are expected to yield more rapid spatial dissusion and heat conductivity than circular drifl urbils. Thus, the confinement properties of an experimental bumpy torus are influenced significantly by the guiding center drift orbits of the individual plasma particles. 
These drift orbits are themselves modified by plasma diamagnetism which alters the magnetic field gradients and also by any static or low frequency electric fields which may arise to ensure quasi-neutrality through ambipolar diffusion of ions and electrons. Turbulence is also neglected in this analysis.

In the bumpy torus, the particle guiding centers drift about the ring axis with an angular velocity, $\Omega$, determined by the curvature, field gradients, and radial electric field. Superimposed on this is a perpendicular toroidal drift velocity, $v_{0}$, caused by the toroidal curvature. Both $\Omega$ and $v_{0}$ are functions of the pitch angle, the particle velocity, and the particle energy. Collisions between particles cause the pitch angle to change; hence $\Omega$ and $v_{0}$ change, causing the guiding center orbits to change. This results in a radial diffusion of particles.

From the linearized kinetic equation, the diffusion coefficient as given by Kovrizhnykh [68] is:

$$
D=v_{0}^{2} \frac{v}{\Omega^{2}+v^{2}}
$$

where

$$
v_{0}=\frac{1}{B e R}
$$

$\nu$ is an effective collision frequency, and $R$ is the average toroidal curvature, which is approximately equal to the major radius of the torus. The plasma confinement time is then given by

$$
\tau=\left\{\begin{array}{lll}
\left(\frac{a}{v_{0}}\right)^{2} \nu & \text { for } \nu \gg \Omega \quad[\text { collisional]; } \\
\left(\frac{R}{a}\right)^{2} \nu^{-1} & \text { for } \nu \ll \Omega & {[\text { collisionless }]}
\end{array}\right.
$$


where $a$ is approximately equal to the minor radius. It is interesting that, in the collisionless case, the particle confinement time is $(R / a)^{2}$ times longer than the classical mirror confinement time.

\subsubsection{EBT Plasma Modes}

Depending on the applied microwave power level and the ambient neutral gas pressure, any one of three distinct, reproducible modes of operation may be measured by a microwave interferometer at $75 \mathrm{GHz}$ along the plasma diameter, $\ell$. These modes are clearly distinguished by the density fluctuation level, $\Delta n \ell$; the stored energy in the stabilizing rings, $W_{\perp}$; and the ambipolar space potential, $V$.

At the highest pressures, the plasma temperature and the ring energy $(\beta)$ is low. Ambipolar potentials are small and generally positive with respect to the cavity wall. No gross instabilities are seen, but low amplitude fluctuations in density are observed in frequency ranges suggestive of drift wave phenomena. This regime, called the "Cmode," is easily distinguishable by the large amplitude, density fluctuations observed on the microwave interferometer. In the $\mathrm{C}$-mode, most of the microwave power is dissipated in generating a cold plasma in which the electron energy relaxation is so rapid that very few hot electrons are generated. In this case, the particle transport is better described by a phenomenological diffusion coefficient which is given by Yoshikawa [69] as

$$
D \simeq \frac{k T e}{e B}\left|\frac{\tilde{n}}{n}\right|^{2} \sin \alpha,
$$

where $\tilde{n}$ is the fluctuating part of the density and $\alpha$ is the phase difference between the density and potential fluctuations. 
At lower pressures, the stabilizing ring stored energy, $w_{1}$, increases significantly and the fluctuation amplitude as a function of the hot electron ring $\beta$ drops to very low values $\left(\left|\frac{\Delta n \ell}{n \ell}\right| \leq 3 \times 10^{-3}\right)$, as shown in Fig. 6. In this regime both the toroidal and annular plasma components are free from gross instabilities and the bulk electron and ion temperatures rise by more than an order of magnitude. A positive space potential of several hundred volts is measured at the high $\beta$ rings with recent measurements [70] showing a negative potential well in the interior of the plasma. This regime is called the "T-mode."

At still lower pressures, the plasma undergoes an abrupt transition in which the stored energy increases to $\beta>0.5$, the floating potential at the plasma edge becomes very large and negative, and measured values have exceeded $10^{4} \mathrm{~V}$. Although the annular, mirror-confined component appears to remain free of gross instabilities, the low density toroidal component supports large amplitude fluctuations. This regime is called the "M-mode." Āthough we shall be mainly interested in the T-mode, the $M$ mode, with its high energy density and large eleclric rields, would be an interesting plasma to study.

The transition between the $\mathrm{C}$-mode and the T-mode is observed experimentally to be a function of the neutral qas pressure and the microwave power input,

$$
\log p_{0}-a_{1} \log p-b_{1},
$$

where $P_{0}$ is the ambient hydrogen pressure and $P$ is the toroidal microwave power input. The critical $\beta$ at the $C-T$ transition for the relevant machine parameters was estimated to be $7 \%$ in reasonable agreement with the theory 


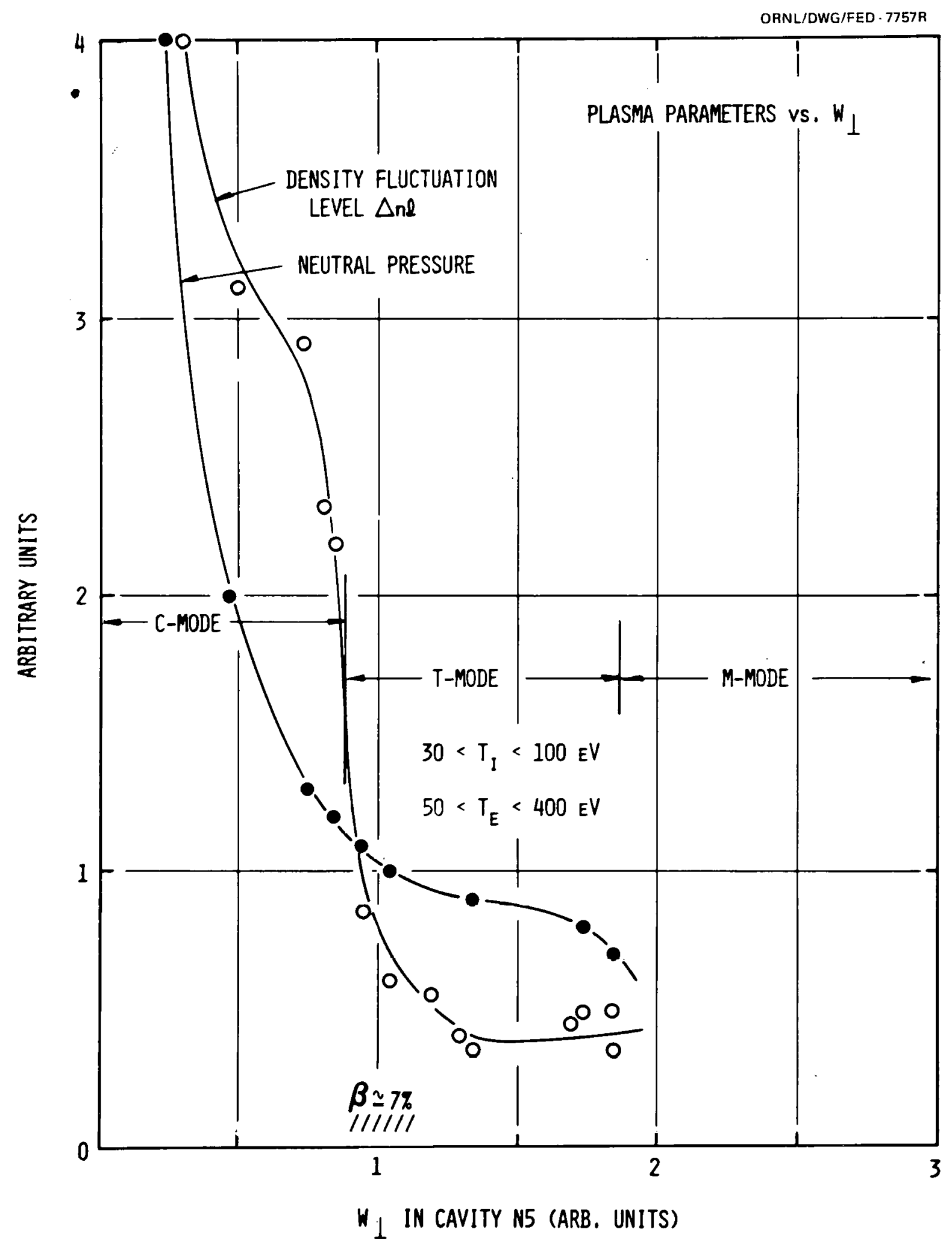

FIG. 6. Plasma parameters vs $W_{\perp}$. 
discussed earlier. The hot electron annulus is observed to form a narrow belt in the midplane; its radial location determined by the location of the fundamental of the profile heating frequency as well as the second cyclotron harmonic resonance of the bulk heating frequency.

It must be kept in mind that outside the hot electron annulus where the stability condition [Eq. (10)] is not satisfied, the plasma is dilute, cold, and unstable. Therefore, the density profile in the T-mode is steep near the hot electron annulus and rather flat inside. This is also confirmed by the existence of localized drift waves on the surface of the plasma column, as well as by the distribution of the $\mathrm{H \alpha}-1$ ine intensity detected by a scanning mirror across the plasma cross section. The diameter of the well-confined plasma was determined typically to be $20 \mathrm{~cm}$ when the magnetic field intensity on the axis of the midplane is $5 \mathrm{~kg}$.

As the neutral gas pressure is decreased the energy stored in the hot electron annulus increases, and the average values of the plasma parameters indicate improved confinement and heating. Ultimately, however, as a critical pressure is approached, the plasma undergoes the abrupt transition into the turbulent M-mode.

Experimentally, the critical pressure for the T-mode transition is found as a function of the microwave power input, similar to the critical condition for the C-T transition,

$$
\log p_{0}=a_{2} \log P-b_{2},
$$

For the T-M transition, the critical pressure for an input power of $50 \mathrm{~kW}$ was observed to be $5 \times 10^{-6}$ Torr. 


\subsubsection{Plasma Parameters and Measurements}

For obvious reasons, the T-mode is the main regime of interest for study of the dependence of plasma temperature on various machine and control parameters.

Thomson scattering of laser light gave a direct spatial measurement of electron energy, but for typical EBT densities the intensity of the scattered laser radiation was marginally detectable. However, steadystate experimental operation allowed data from multiple laser pulses to be accumulated and electron temperatures of 130 to $200 \mathrm{eV}$ were measured when using low microwave power heating $(20 \mathrm{~km})$.

The linear density of electrons as measured by the 70-GHz microwave interferometer gives $\langle n \ell\rangle \sim 3 \times 10^{13} \mathrm{~cm}^{-3}$.

$X$-ray spectroscopy has long been one of the standard measurement techniques for microwave-heated, hot electron plasmas, because bremsstrahlung spectra observed using this technique give details of the energy distribution over the range of $1 \mathrm{keV}$ to several MeV. Soft $\mathrm{x}$-ray bremsstrahlung measurements have also been used to obtain the bulk electron temperatures ranging from 100 to $400 \mathrm{eV}$.

Charge-exchange neutrals have an energy spectrum showing typical bulk temperatures of 30 to $90 \mathrm{eV}$. Observations in the T-M transition show the spatially averaged, ion energy distribution to consist of two components: a thermal (Maxwcllian) distribution with average energy of about $100 \mathrm{eV}$ and a high energy group several hundred $\mathrm{eV}$, which is also Maxwellian. Since this transitional region has been little studied, these energetic ion tails are not yet understood. 
To summarize the plasma parameters in the T-mode: $n_{e}$ (toroidal) $1-3 \times 10^{12} / \mathrm{cm}^{3} ; \mathrm{T}_{\mathrm{e}}$ (toroidal) $\sim 50-300 \mathrm{eV} ; \mathrm{T}_{\mathfrak{j}}$ (toroidal) $\sim 30-100 \mathrm{eV} ;$ $\mathrm{n}_{\mathrm{e}}$ (annulus) $\sim 7-4 \times 10^{11} / \mathrm{cm}^{3} ; T_{\mathrm{e}}$ (annulus) $\cong 250 \mathrm{keV}$; annulus beta $0.1 \lesssim \beta \leqslant 0.4$. One set of toroidal plasma parameters deducible from our present diagnostic system, including estimates of microwave power dissipated in circuitry, surface plasmas, and ring plasmas gives an estimated toroidal energy confinement time of $7 \mathrm{msec}$, a value in reasonable agreement with both the measured and calculated particle confinement times of 15-30 milliseconds. A comparison of this energy confinement time with both neoclassical transport and with Bohm is shown in Fig. 7, in fairly good agreement with Eq. (15b). It should also be mentioned that EBT, as a consequence of the open outer drift surfaces and the ambipolar electric field on the ring plasma surface, exhibits high plasma purity. Field error studies showed an interesting behavior but no perceptible difficulties with magnetic field errors or convective cells.

\subsubsection{Other Microwave Heated Bumpy Tori}

The ELMO Bumpy Torus-I became EBT-S with the addition of more than 50 $\mathrm{kW}$ of 28-GHz power in June 1978, thus permitting bulk densities higher than $4 \times 10^{12} \mathrm{~cm}^{-3}$.

The Nagoya Bumpy Torus of the Institute of Plasma Physics, Nagoya University, started its operation at a similar power level and scale during 1978.

On the basis of these studies, EBT-II was conceived as a 30- to 60-kG superconducting, 48-coil, bumpy torus heated by 2.4 MW of millimeter microwave power to keV temperatures at densities of $5 \times 10^{13} \mathrm{~cm}^{-3}$. The design base used a 5-meter major radius with a $30: 1$ aspect ratio. This experimental facility is expected to come into operation in the early 1980s. 
NEOCLASSICAL THEORY FOR CONFINEMENT OF EBT PLASMA

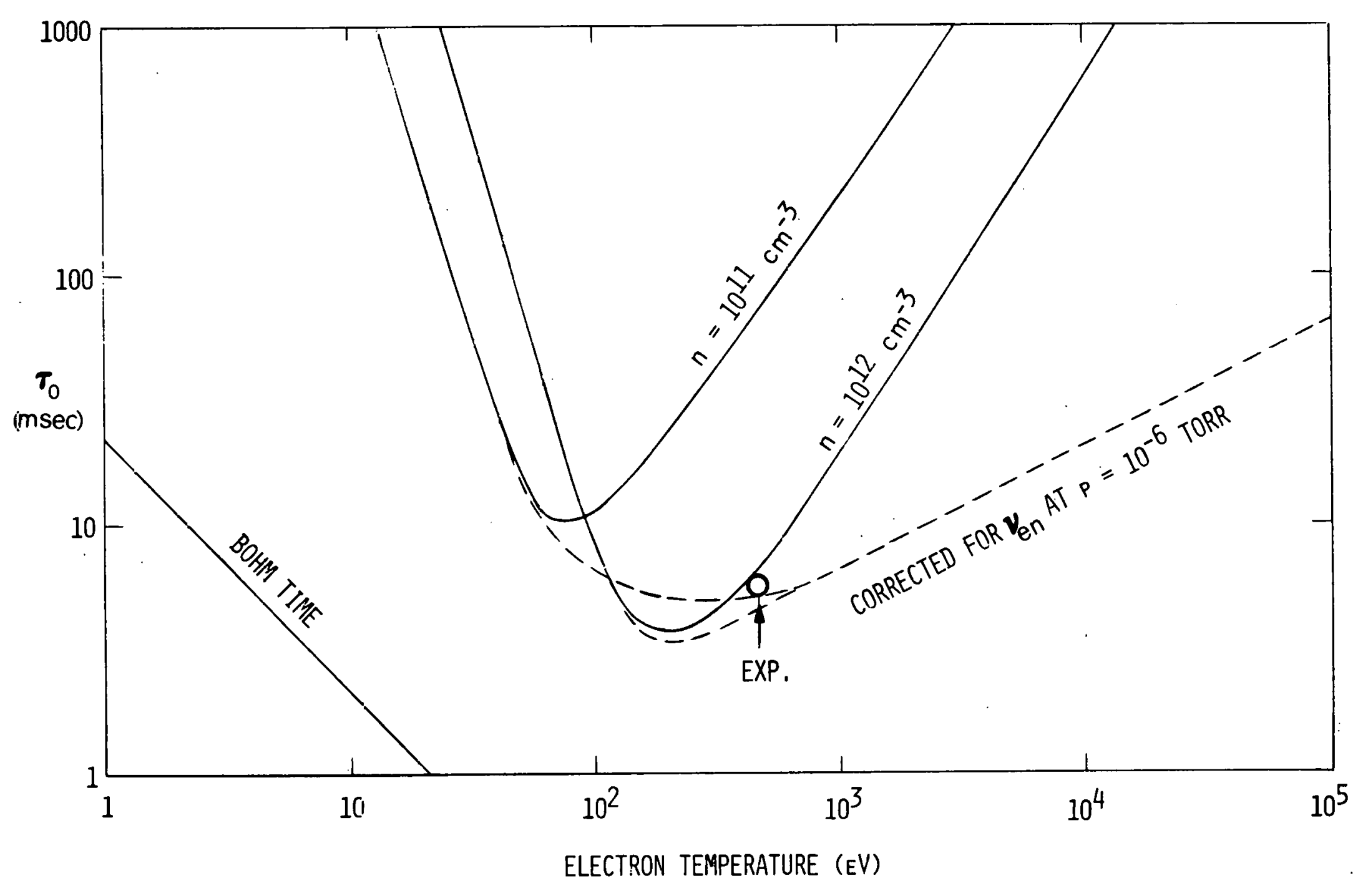

FIG. 7. $\tau_{e}$ vs $T_{e}$. 


\subsubsection{EBT as a Reactor}

The experimental results from EBT have motivated a consideration of the EBT concept as the basis for a potential reactor [71]. A large,

power-producing EBT reactor system might be especially attractive because of the possibility of steady-state operation at high plasma pressure.

Assuming neoclassical collisionless confinement, it is not surprising that no fundamental difficulties have been found in extrapolating conceptual EBT designs to intermediate power reactors in the 500-MW to 2000-MW range. The additional assumption of adequate microwave power sources at a frequency of $170 \mathrm{GHz}$, although judged possible, is certainly not trivial.

From the nuclear engineering point of view, the large aspect ratio inherent in the EBT concept eases the accessibility problems encountered in most other toroidal device designs. Microwave heating of the EBT plasma has proved to be very effective experimentally, and design studies of larger devices, even up to the reactor size level, indicate that, in principle, this heating method offers many advantages. 


\section{TECHNOLOGICAL APPLICATION OF MICROWAVE HEATING}

\subsection{GENERAL CONSIDERATIONS}

As evident from the previous discussions, the formation and heating of fusion plasmas by application of microwave power at the electroncyclotron frequency is an efficient technique not only when used alone as in EBT [16-17], but also when used in combination with other heating methods [10]. Although the method is, in principle, applicable to almost any fusion device utilizing magnetic confinement, a significant technological constraint on extension of the method currently lies in the limited availability of suitable high power microwave sources at frequencies appropriate to resonant magnetic fields of several tens of kilogauss. The advantages of ECH are sufficiently great, however, to warrant a significant development effort to overcome present microwave power source limitations. Such efforts are now under way in both the U.S.A. and the Soviet Union.

An often understated advantage of $\mathrm{ECH}$ is the relative ease with which the power input to the plasma may be controlled over a wide range. ECH systems employing either single or multiple rf amplifier output devices can be simply provided with smooth, infinite resolution control over rf power output by control of drive power at a low rf level. The rf power output of systems employing oscillator output devices may be controlled by variation of supply voltages. Negative feedback may be employed to control and stabilize the output of either device type by applying a signal proportional to $r$ f output to an appropriate control electrode (e.g., the accelerating anode of the electron gun). Power 
level as a function of time may thus be varied or maintained with almost any desired degree of precision. Rf bandwidths ranging upward from tens of megahertz provide additional options for application of feedback, including stabilization and programming of plasma parameters, with almost any required speed of response. Capability for both extreme flexibility and high reliability can thus be provided by appropriate design.

Waveguide transmission systems are generally employed for ECH applications. Dominant mode waveguide is useful for transmission at multikilowatt levels in the frequency range below $35 \mathrm{GHz}$. However, due to considerations of ohmic losses and voltage breakdown, oversized waveguides capable of supporting multiple electromagnetic propagating modes are required for high power transmission in the millimeter wavelength region. Efficient transmission in such multimode systems requires careful design to minimize $I^{2} R$ propagation losses associated with "spurious" higher order modes and especially to minimize losses assoriated with energy storage of such modes. ECH sy3tems constrainls dre fortunately well-suited to minimize the latter effect because the waveguide cross section normally need not be constricted at its entry to the fusion device. Bends may be incorporated in waveguide transmission systems, permitting flexibility in the location of rf sources relative to the fusion device. Use of the low loss $\mathrm{H}_{0 \mathrm{n}}$ family of circular electric modes is especially attractive in the millimeter wavelength region because of efficiency and power handling considerations. Although hollow metallic waveguides have inherent self-shielding advantages, free space transmission of millimeter wave power for ECH is also a viable alternative in cases where imperfect shielding may be tolerated [72]. 
Waveguide vacuum window availability has formerly presented few problems in ECH systems, since window designs used on microwave output tubes are generally applicable for use at equivalent power levels on the fusion device. As an alternative, completely windowless systems employing fast acting vacuum valves in the waveguide system are considered feasible for future applications requiring very high power and short wavelength if the realizability of waveguide vacuum windows should become a basic limitation. In general, however, the use of waveguide vacuum windows is highty desirable because the manufacture and application of microwave tubes are thereby simplified and because differential vacuum pumping requirements common to some other plasma heating methods are thereby eliminated. Window location is flexible in ECH systems because the window may be located at an arbitrary distance from the wall of the fusion device and may be readily shielded from plasma bombardment by interposing waveguide bends. A complication arises when the waveguide itself must pass through a magnetic field region where $\omega=\omega_{c e}$ (as in the case of a min-B). In order to prevent breakdown and arcing in such regions, the waveguide vacuum window has been located in the strong field region where $\omega<\omega_{\text {ce }}$, thereby maintaining pressurized waveguide operation through the spurious electron-cyclotron resonance region.

Acceptable impedance matching of $\mathrm{ECH}$ transmission systems to fusion devices may be readily achieved. Because the physical dimensions of fusion devices are much greater than $\lambda$ and due to the efficient power absorption and resulting low $Q_{e f f}$ of fusion devices in normal ECH operation where $\omega>\omega_{p e}$, matching considerations are greatly simplified. A 
power density of $\approx 5 \mathrm{~kW} / \mathrm{cm}^{2}$ per port has been routinely employed. An increase of an order of magnitude or more, up to the operating limit of the waveguide, is considered possible, barring adverse near-field effects. Simultaneous application of ECH power through multiple entry ports and from multiple power output devices is not only feasible, but also generally desirable, due both to increased versatility in heating distribution and to the enhanced reliability attained through redundancy. Application of ECH power at multiple frequencies for the purpose of simultaneousiy heating several regions of the device is also accomplished routinely. A distinct advantage of $\mathrm{ECH}$ over some other plasma heating methods is that individual port openings need be no larger than the waveguide cross section. Interactive coupling between ports is minimal due to the low $Q_{\text {eff }}$ and the large ratio of total wall area to port area. ECH systems have demonstrated very low sensitivity to changing plasilid cundttions when operated under normal conditions of $\omega>\omega_{\mathrm{pe}}$.

Pcrhaps the most allractive advantage of ECH lies in the high efficiency with which microwave energy is transferred to the plasma. High efficiency of energy transfer is ensured by the large absorption coefficient of plasmas at electron-cyclotron resonance and by minimizing losses in the coupling system, Since hnth microwave transmission lines and dc power supplies may be made very efficient, the attainable overall efficiency of conversion of line power to plasma heating is limited primarily by the dc-to-rf conversion efficiency of the high power microwave tubes. This efficiency factor, and thus the overall system effi.. ciency, can range upward from $30 \%$ in utilization of 1 ine power for 
plasma heating. Overall ECH system efficiency may therefore be made competitive with, if not superior to, that obtainable with other plasma heating methods.

\subsection{PLASMA COUPLING METHODS}

A fundamental consideration in power transmission in all rf systems is that of impedance matching. In addition to providing for maximum power transfer (i.e., maximum efficiency), impedance matching is important in high power systems for prevention of adverse effects of reflected power upon the rf power source and waveguide transmission system components, e.g., overheating, arcing, and voltage breakdown. Due to the time-varying quality of plasmas, which ultimately constitute the rf load in ECH systems, classical methods of impedance matching, using networks of passive elements, are very difficult to apply. It is therefore necessary to resort to empirical methods. Even though the plasma is enclosed by a chamber having walls which are highly reflective at microwave frequencies (i.e., walls of high electrical conductivity and with suitable precautions against microwave leakage from joints or openings), one can minimize local plasma coupling in the near-field of the waveguide coupling aperture and thereby achieve high efficiency coupling to the plasma with low reflections over a wide range of plasma conditions.

In the manner described in Section 3, ECH power which is fed into the plasma chamber undergoes multiple low loss reflections with accompanying changes in polarization and direction. The $Q_{0}$ of the plasma chamber without the plasma present is therefore very large. However, with magnetic field surfaces at electron-cyclotron resonance present in 
the chamber, the extraordinary wave is heavily damped by absorption during its transit through a resonance region. Because polarization and directional changes accompany successive reflections (resulting in reflected waves comprising both ordinary and extraordinary waves), the total input wave is soon converted to extraordinary waves and is rapidly damped by coupling to the plasma. The resulting loaded $Q$ of the chamber is then very low. The overall action may be visualized by comparing it to that attained by coupling to a lossy dielectric medium which partially fills and is enclosed by a large multimode cavity. Input power is dissipated in the dielectric medium with high efficiency and with little variation due to size, shape, or location of the medium within the cavity so long as local interaction with the incident. wave in the nearfield of the coupling aperture is small. In a similar way, coupling of $\mathrm{ECH}$ power to the plasma is relatively unaffected hy the shape or exact lucation of cyclotron resonant mod-B magnetic field surfaces, as long as these surfaces lie outside the near-field of the coupling aperture.

An important additional step in minimizing near-field interaction between the coupling aperture and the plasma is attained by orienting the input waveguide with EllB such that the ordinary wave is preferentially launched into the chamber. Because the ordinary wave propagates readily through the plasma under normal conditions of $\omega>\omega_{p e}$, near-field interaction is minimized and significant plasma coupling occurs only after subsequent reflection from the chamber walls in the manner previously described. From the standpoint of the microwave transmission system, the advantage of launching with EIIB is a significant reduction in reflected power and resulting standing waves over a very wide range of plasma 
conditions. An additional advantage (though perhaps a less obvious one) of this launch polarization is that $\mathrm{ECH}$ power is distributed more uniformly throughout the cavity, resulting in more uniform heating throughout the plasma volume.

Because the effective loaded $Q$ of the ECH multimode cavity is very low under normal conditions where $\omega>\omega_{\text {pe }}$, the impedance presented to the input wave is nearly equal to the impedance of free space. Impedance matching considerations for design of the coupling aperture are then similar to those for a radiating antenna. The simplest such aperture suitable for high power use is an open-ended waveguide terminating flush with the interior wall of the cavity. Such an aperture, used as an antenna in dominant mode waveguide, presents an impedance mismatch resulting in VSWR of $\approx 1.8: 1$ [73]. A considerably lower VSWR may be attained by using an oversized waveguide or by flaring the waveguide walls, as in a horn antenna, and thereby utilizing a larger aperture. A widely used and beneficial method of coupling from dominant mode waveguide employs quadrature-type waveguide hybrid junctions terminating in two identical radiating apertures at the cavity wal1, as described in Ref. [74]. In this method, the combination of network properties of the hybrid junction and physically symmetrical connection of the output ports is used to produce high order cancellation of mismatch effects caused by discontinuities and some cancellation of mismatch effects causèd by near-field interaction with the plasma. Additional decoupling from near-field effects is obtained by orienting the feed with EllB as described above. As an example of the effectiveness of this method, an 
average VSWR of $<1.4: 1$ and a peak VSWR of $<2.0: 1$ have been observed on EBT-I for all of the 48 feeds associated with both ECH systems over the full range of power input under normal conditions.

Acceptable impedance matching has been obtained in the millimeter wave region by terminating the oversized waveguide flush with the interior surface of the cavity. The complex electromagnetic field patterns associated with higher mode propagation in such multimode transmission lines obviously do not permit launching of the ordinary wave with high purity. The wave which is launched is in general, however, a combination of ordinary and extraordinary waves resulting in greatly reduced sensitivity to near-field effects as compared to the case where the extraordinary wave is launched from dominant mode waveguide with $E_{\perp} B$.

Due to efficient absorption and to plasma shielding effects, microwave power fed into one mirror confinement region of EBT does not readily propagate into adjacent regions. It has accordingly been neceszary to provide a discrete ECH input to each of the 24 mipror confinement regions. This is necessary in order to form and maintain the high $\beta$, hot electron annuli upon which stability depends, as well as to provide uniform heating of the entire volume. This has necessitated the use of a complex dominant mode waveguide power division network to derive 24 inputs of equal level from no greater than four output tubes in each power source, Such an arrangement affords great. flexihility and permits precise control over individual input levels for diagnostic purposes. Such networks are difficult to realize in multimode transmission systems, however, due to the problem of achieving the necessary components and to the sheer bulk of such an apparatus. 
An alternative approach, which is being pursued in connection with EBT-S and future systems, is to combine all or several mirror confinement regions of the bumpy torus into a single multimode cavity. This may be accomplished by connecting the desired number of confinement regions to a large external reflecting chamber via identical oversized waveguides entering along the minor radius. Figure 1 shows that no spurious cyclotron resonant regions are involved with this arrangement of entry, and no such regions are likely to interfere in the external reflecting chamber, because the magnetic fields everywhere outside the torus are quite small. In this way, ECH power fed from the source into the external reflecting chamber via oversized waveguide is coupled into several regions simultaneously. Some degree of balance between power inputs to individual regions is provided by the large $Q_{0}$ of the reflecting chamber and by symmetry in the connections. An additional degree of balance and an increase in overall efficiency result because power reflected from one region is avallable for absorption in another. Additional control of power distribution may be obtained by the use of irises or "stops" to limit power fed to a selected region or to remove it entirely. Attractive possibilities exist for combining the functions of the external reflecting chamber with those of the external vacuum manifold. This method may also be used to improve the uniformity of plasma heating in other types of fusion devices through use of multiple ECH power feeds. 


\subsection{MICROWAVE POWER SOURCES}

Applicable microwave device (tube) types for ECH microwave power sources are generally limited to those with basic suitability for continuous wave $(\mathrm{cw})$ operation. Although pulsed applications exist in tokamak heating as well as in other types of fusion devices, power output durations of milliseconds or greater are usually required, and such pulse durations exceed practical values of critical thermal time constants for most millimeter wave devices. Dcvices may be tailured especially for such long pulse applications at low duty cycles by opti= mization of thermal characteristics and use of pulsed power supplies. The principal benefit in such cases is realized through reduction in cost and complexity of power supplies, cooling systems, and associated equi pment.

Almost any high power cw microwave device capable of producing power output at the required frequency can be used for $\mathrm{ECH}$, providing the application requirements for the device can be met. The output stage of an ECH source may be made up of one or many similar deviress. Due to requirements for power supplies and auxiliary equipment, lowest system cost and highest reliahility usually result when the device having the grealesl puwer output at the required frequency is used, thus minimizing the number of devices. Power output of sources utilizing multiple output devices need not be combined into a single waveguide but rather may be transmitted to the plasma device by separate waveguides from each output device. Such an arrangement not only offers advantages in reducing power handling problems in large systems, but also produces more balanced excitation of the device through the use of multiple feed points. 
Amplifier power output devices are preferred over oscillators because of the simplicity and flexibility of power output control. The power output of many amplifiers may be controlled simultaneously by adjustment of a common low level drive power source. The power output of oscillator devices must be controlled by variation of supply voltages. In addition to these differences, the power output of an oscillator is likely to be more sensitive to changes in output load impedance, depending on the inherent degree of isolation of output load reflections from the internal feedback path. Aside from these basic considerations, amplifiers and oscillators are equally applicable for use in ECH sources. Some possibilities for use of external negative feedback for stabilization and control were mentioned above. Some detailed considerations for ECH power source protection and control and for high power transmission line practice as applied to ECH systems are given in Ref. [74].

Countless $\mathrm{CW}$ devices suitable for ECH, developed for other applications, are readily available in the lower frequency portion of the microwave spectrum. Klystron amplifiers have been widely used at frequencies up to $18 \mathrm{GHz}$, and $\mathrm{cW}$ magnetrons have been used at frequencies up to $9 \mathrm{GHz}$. TWT amplifiers employing coupled cavity, slow wave structures have been used for ECH at multikilowatt $\mathrm{cW}$ power output levels at frequencies up to $55 \mathrm{GHz}$. Pulsed gyrotron oscillators operating in the millimeter wavelength region have been used for $E C H$ in the Soviet Union. A CW gyrotron oscillator operating at $28 \mathrm{GHz}$ is used on EBT-S. 
Projected requirements of ECH sources for future application in the EBT program and for heating large tokamaks include multimegawatt $\mathrm{cW}$ power levels at frequencies in the range of 100-150 GHz. Microwave devices having power output capability consistent with these requirements are not presently available and are currently the object of intensive development. The principal 1 imitation in extension of power output capability of devices at higher frequencies is that of power density in the $r f$ interaction structure, because the dimensions of such structures are proportional to wavelength. An additional $I^{2} R$ thermal burden proportional to $\lambda^{-1 / 2}$ results from high frequency skin effect as frequency is increased. Simple scaling therefore predicts power proportional to $\lambda^{5 / 2}$ for a given power density in the $r f$ structure. This scaling relationship is modified through increase in the axial dimensions of linear beam rf structures when relativistic beams are employed. Development of high power $\mathrm{CW}$ millimeter wave devices for $\mathrm{ECH}$ is facilitated because many traditional performance constraints placed upon communications tubes are unimportant in the ECH application. Further benefit is derived from the stationary nature of the application, which makes size, weight, and auxiliary equipment requirements of secondary importance.

The basic class of devices which presently offers the groatest promise for achieving ECH power source needs is the cyc.lntron resonance maser (CKM), which was first descrlbed by Hirshfield and Wachtel [7b]. The gyrotron oscillator, a form of CRM, has been the object of intensive investigation in the Soviet Union. The achievement by Zaytsev et al. [76] of $>10-\mathrm{kW} \mathrm{cW}$ power output from a gyrotron at $\lambda=3 \mathrm{~mm}$ with an efficiency of $>30 \%$ is notable. Varian Associates in the U.S.A. is 
currently developing a 28-GHz gyrotron with the objective of $200-\mathrm{kW} \mathrm{cW}$ output capability from a single device. The $28-\mathrm{GHz}$ gyrotron is a low frequency prototype for a later device to produce $200-\mathrm{kW} \mathrm{cW}$ output at $110 \mathrm{GHz}$. The $200-\mathrm{kW}, 110-\mathrm{GHz}$ device is intended as a basic building block for future multimegawatt $\mathrm{ECH}$ sources in the U. S. A.'s fusion energy effort.

\subsection{EBT-I MICROWAVE HEATING SYSTEMS}

The microwave heating systems used for plasma formation and ECH in EBT-I [16-17] are briefly described. Basic specifications for the systems are shown in Fig. 8. Two separate microwave power sources are employed. The primary resonant heating source produces power output up to $60 \mathrm{~kW} \mathrm{cW}$ at a frequency of $18 \mathrm{GHz}$. The power output of this source is divided into 24 equal parts which are distributed to the 24 regions of the torus. The lower resonant heating source, used for profile heating, produces power output up to $30 \mathrm{~kW} \mathrm{cW}$ at $10.6 \mathrm{GHz}$, and also provides 24 outputs of equal level - one to each region of the torus.

A block diagram of the $60-\mathrm{kW}, 18-\mathrm{GHz}$ primary resonant heating source is shown in Fig. 9. This source is comprised of four type VA934A2 5-cavity CW klystron amplifiers as manufactured by Varian Associates, Palo Alto, California, U.S.A. Each of these klystron amplifiers has $\approx 50 \mathrm{~dB}$ gain, is liquid cooled and magnetically focused by an external electromagnet, and requires a beam voltage supply of $21 \mathrm{kV}$ at 3.2-A capacity which is isolated from ground for monitoring of body current intercepted by the $r f$ structure. Drive power for the four klystron amplifiers is derived from the output of a single reflex klystron 
ORNL-OWG 77-3694

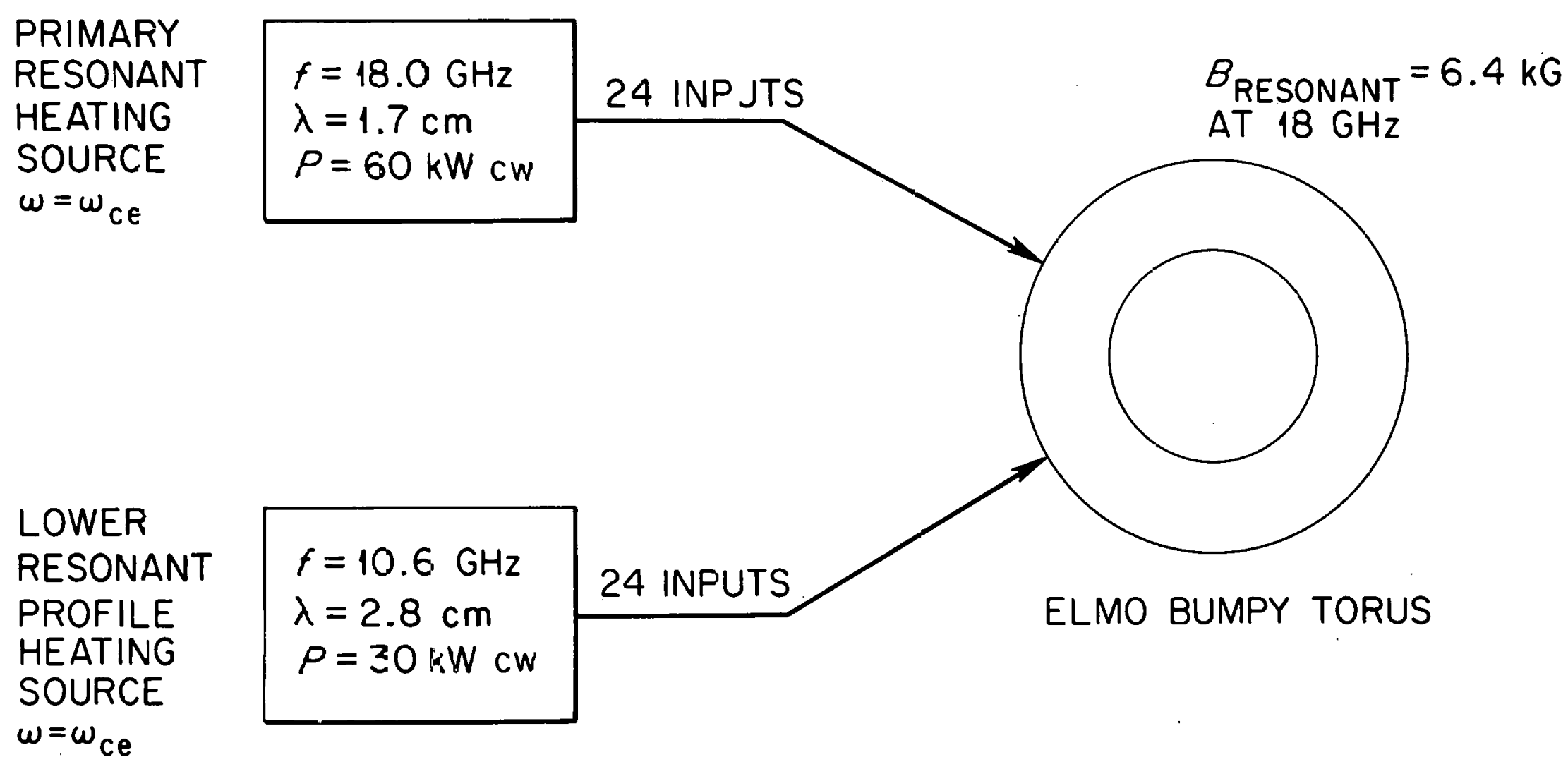

FIG. 8. EBT microwave heating. 
ORNL.OWO nESW

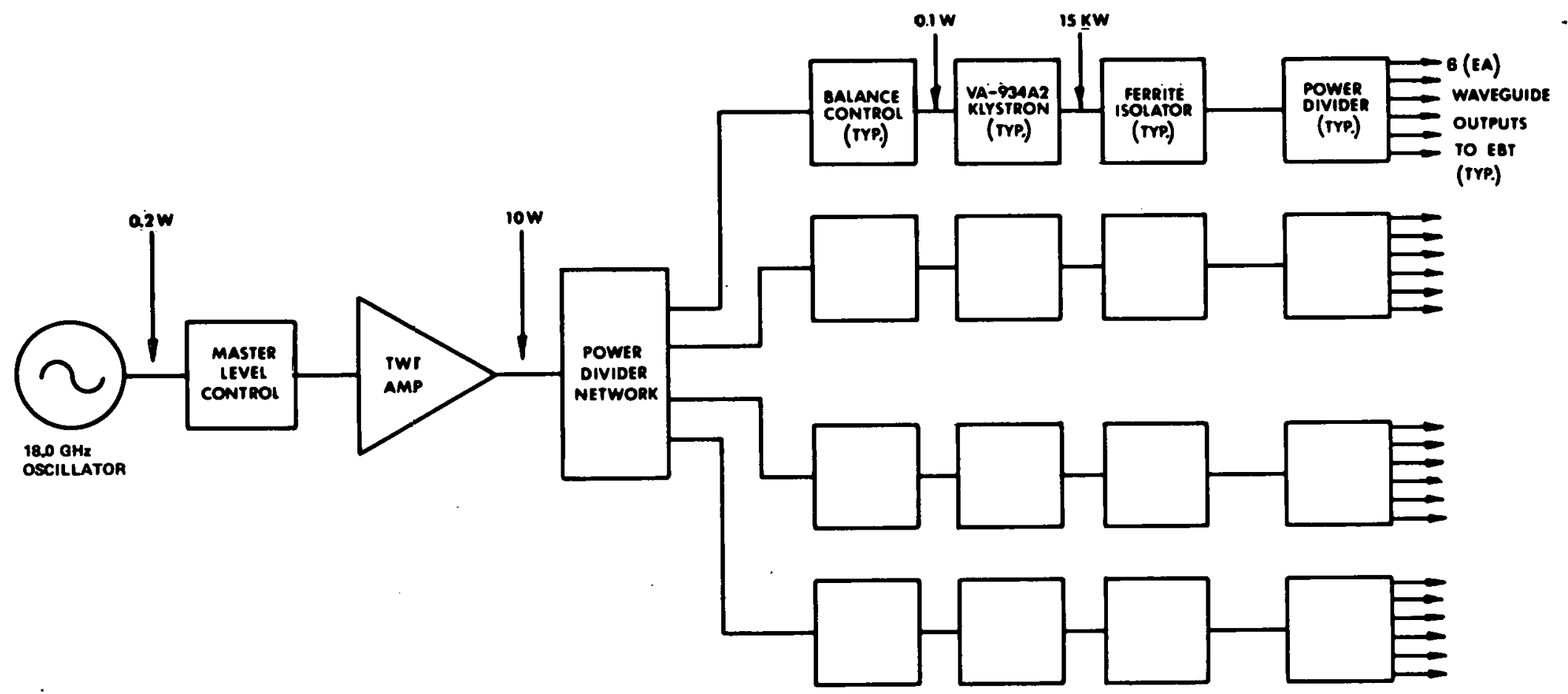

FIG. 9. EBT resonant heating power source $-60 \mathrm{~kW} \mathrm{cW}$ at $18 \mathrm{GHz}$. 
oscillator, augmented by a small TWT amplifier, and is divided four ways by a power divider network consisting of hybrid junctions. A single master level control attenuator serves to control the drive power level and thus to control the output power level of all klystron amplifiers simultaneously. Balance control attenuators are included at the input of each klystron amplifier to compensate both for differences in power gain between tubes and for differences in attenuation due to unequal lengths of the input waveguides. The water cooled WR-62 dominant mode waveguide output of each klystron amplifier is equipped with a reverse power directional coupler and crystal detector for sensing power reflected by an arc in the waveguide system. Characteristically, cw waveguide arcs propagate toward the power source and, unless promptly extinguished, can destroy the output waveguide window of the tube. The amplified output signal from the crystal detecton is used to activate a crystal switch for removal of drive power from the tube, thereby extinguishing the arc within a few microseconds after it occurs. Simultaneous activation of the beam supply crowbar by the crystal detector signal provides redundant protection. In other systems, additional redundancy is provided by activation of the protective circuitry through optical sensing of the light produced by a waveguide arc.

The output waveguide of each klystron amplifier in Fig. 9 is directed through a 4-port. differential phasc shift ferrite circulator, connected as a load isolator by installation of high power matched terminations on appropriate ports. The circulator serves to isolate the klystron amplifiers from the adverse effects of reflected power produced by either load mismatch or waveguide arcs in the transmission system 
beyond. Protective circuitry activated by reflected power signals at the circulator output provides additional arc protection. The output of each circulator is fed to a 6-way power divider network made up of a sidewall directional coupler and sidewall hybrid junctions. The six equal outputs are then fed to six separate regions of EBT. In this manner, the required $24 \mathrm{ECH}$ power inputs to the torus are derived from four output tubes. The possibilities for increased power capability by addition of output tubes and alteration of the power divider networks are obvious. The design of the $30-\mathrm{kW} \mathrm{cW}, 10.6-\mathrm{GHz}$ lower resonant heating source is very similar, except that a total of three 10-kW cW klystron amplifiers are used, with each amplifier feeding one-third of the torus via an 8-way power divider network.

Each of the 24 primary ECH inputs to the EBT is provided with control, monitoring, protective, and coupling circuitry as indicated in Fig. 10. The relative level of input power fed to each region is independently controllable over the full range from zero to maximum by a ferrite variable power divider which functions as a remotely controlled attenuator with a response time of $\approx 0.5 \mathrm{msec}$. Each ferrite attenuator is equipped with a solid-state controller, which may be utilized either with manually selected commands or in a closed loop system to provide control of $\mathrm{ECH}$ power inputs to individual confinement regions in response to external signals. Actual ECH power input to each region is monitored by a forward power directional coupler. A reverse power directional coupler in each feed is used for sensing excessive reflected power and the presence of possible waveguide arcs. These signals operate an rf crystal switch through solid-state logic circuitry to remove the 


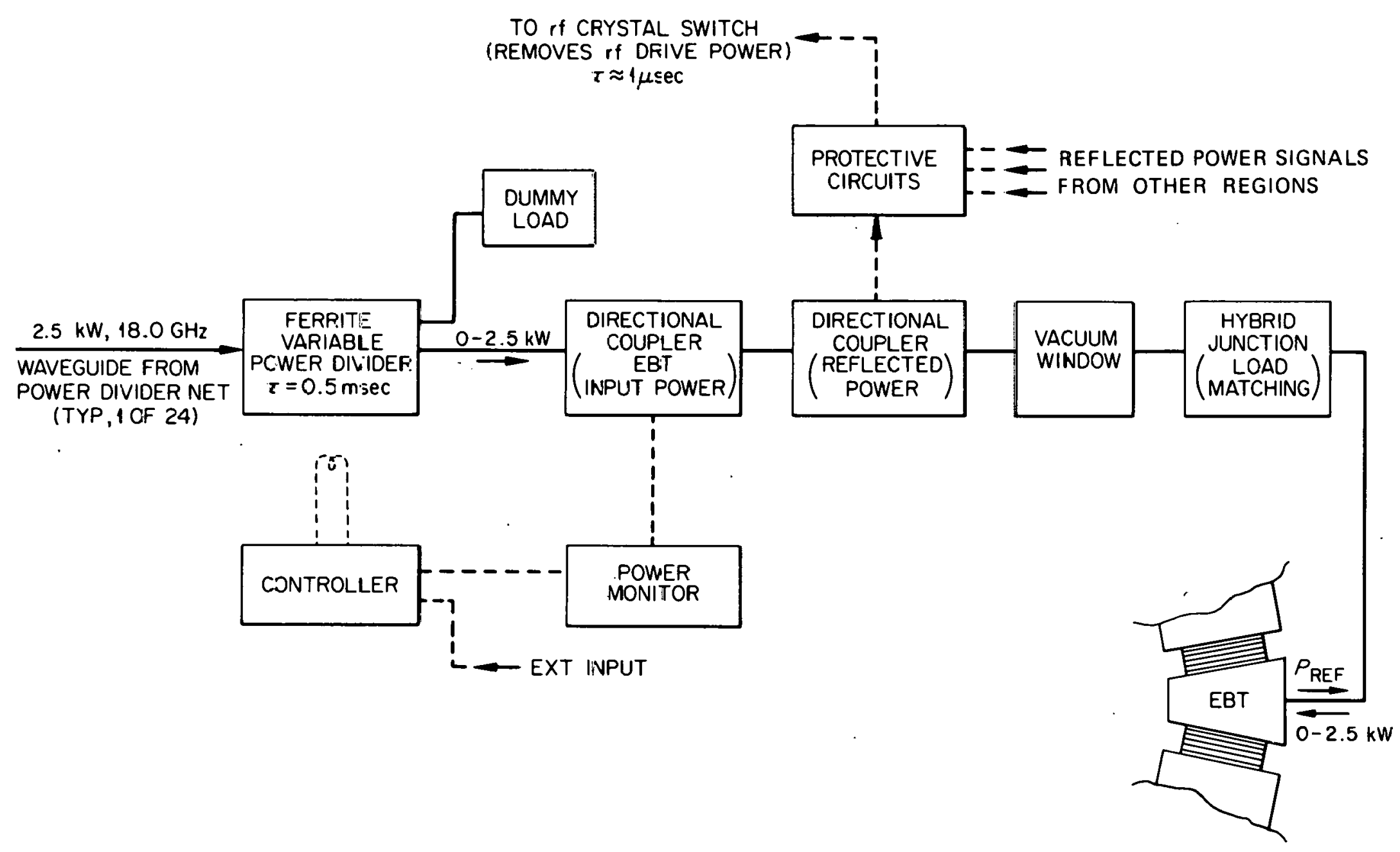

FIG. 10. EBT resonant heating. Typical rf control, monitoring, and protection for each of 24 mirror regions. 
rf drive power from ail klystron amplifiers within $\approx 1 \mu \mathrm{sec}$ if an arc occurs. The waveguide vacuum windows are $\lambda / 2$-thick alumina ceramic of water cooled design similar to those employed in construction of the VA934A2 klystron amplifier. Sidewall hybrid junctions are used for impedance matching and coupling in the manner described in Ref. [74].

A comprehensive system of permissive safety interlocks is incorporated into each system to ensure against operation with improper cooling or beam focusing conditions which would be hazardous for the klystron amplifiers and transmission system components. Additional personnel safety interlocks prevent entry into unsafe areas during operation. Waveguides which operate at power levels greater than $\approx 1 \mathrm{~kW} \mathrm{CW}$ at $18 \mathrm{GHz}$ or $\approx 2 \mathrm{~kW} \mathrm{CW}$ at $10.6 \mathrm{GHz}$ are water cooled to limit temperature rise resulting from $I^{2} R$ losses. This decreases arcing tendency and improves environment for equipment and personnel in close proximity. Waveguides outside the vacuum system are pressurized to $\approx 1$ atm with dry nitrogen. This increases power handling capacity by increasing voltage breakdown potential, prevents entry of moisture or foreign matter, and decreases oxidation of interior surfaces which would result in increased attenuation. Flange joints are lapped by hand to ensure perfect mating of surfaces, and no dielectric gaskets are used in their assembly. In this way, by admitting the pressurizing gas through a limiting orifice, a pressure switch interlock may be used to detect the presence of a loose flange joint or damaged component and thereby prevent system operation. In addition to reducing the probability of waveguide arcs, this precaution aids in preventing inadvertent exposure of personnel to microwave leakage radiation. 
Very reliable operation has been experienced with the ECH systems described. The principal design criteria were the provision of maximum experimental flexibility and good operating reliability. Although transmission efficiency was a secondary consideration, an overall rf transmission efficiency of $72 \%$ has been measured for the $18-\mathrm{GHz}$ system which uses dominant mode waveguide throughout. The systems have undergone numerous evolutionary changes to conform to experimental need. Few modifications were necessary for application as profile heating systems in conjunction with the EBT-S 28-GHz primary ECH systcm. These systems were not chosen for discussion because they are necessarily typical ECH systems, but rather to illustrate some basic design considerations and to provide an example of the manner in which ECH systems may be tailored to the specific needs of the associated plasma facility.

\section{CONCLUSIONS}

To summarize the status of ECH at this time, one could certainly state that the effectiveness and flexibility of the method have been amply demonstrated. However, future applications of ECH could greatly benefit from the development of methods to self-consistently calculate the microwave heating fields in plasma and the further development of very high power millimeter wavelength microwave sources for heating in magnetic fields of hundreds of kilogauss. For assistance and counsel, the authors are very grateful to G. E. Guest, E. F. Jaeger, and the many other people who have contributed to the subject of $\mathrm{ECH}$. 


\section{REFERENCES}

[1] BECKER, M.C., DANDL, R.A., EASON, H.O., ENGLAND, A.C., KERR, R.J., ARD, W.B., Nucl. Fusion: 1962 Supplement, Part 1 (1962) 345 .

[2] CONSOLI, T., HALL, R.B., Fusion NUC1. $\underline{3}$ (1963) 237.

[3] DANDL, R.A., et al., Nucl. Fusion 4 (1964) 344.

[4] ARD, W.B., DANDL, R.A., STETSON, R.F., Phys. Fluids $\underline{9}$ (1966) 1498.

[5] ARD, W.B., DANDL, R.A., ENGLAND, A.C., HAAS, G.M., LAZAR, N.H., in Plasma Physics and Controlled Nuclear Fusion Research (Proc. 2nd Conf. Culham, 1965) II, IAEA, Vienna (1966) 153.

[6] DANDL, R.A., Bu11. Amer. Phys. Soc. 12 (4), 461 (Apri1 1967).

[7] DANDL, R.A., EASON, H.O., EDMONDS, P.H., ENGLAND, A.C., Electroncyclotron heating by 8-mm microwave power in the magnetic facility ELMO, Relativistic Plasmas: The Coral Gables Conference, ed. by 0. Buneman and Wm. B. Pardo, W. A. Benjamin, Inc. (1968) 181.

[8] IKEGAMI, H., et a1., Phys. Rev. Lett. 19 (1967) 779.

[9] IKEGAMI, H., et al., Phys. Fluids 11 (1968) 1061.

[10] DANDL, R.A., et a]., Electron-cyclotron heated 'target' plasma experiments, in Plasma Physics and Controlled Nuclear Fusion Research (Proc. 3rd Conf. Novosibirsk, 1968) II, IAEA, Vienna (1969) 435.

[11] BADET, R., et al., Nucl. Fusion 15 (1975) 865. 
[12] ANDERSON, O.A., BIRDSALL, D.H., HARTMAN, C.W., LAUER, E.J., FURTH, H.P., in Plasma Physics and Controlled Nuclear Fusion Research (Proc. 3rd Conf. Novosibirsk, 1968) I, IAEA, Vienna (1969) 443.

[13] ARD, W.B., BLANKEN. R.A., COLCHIN, R.J., DUNLAP, J.L., GUEST, G.E., HASTE, G.R., HEDRICK, C.L., LAZAR, N.H., SIGMAR, D.J., in Plasma Physics and Controlled Nuclear Fusion Research (Proc. 4th Conf. Madison, 1971) II, IAEA, Vienna (1971) 619.

[11] SPROTT, J.C., Phys. Tluids 14 (1971) 1795.

[15] OKABAYASHI, M., VOITSENYA, V., RIPIN, B., SCHMIDT, J., YOSHIKAWA, S., Phys. Fluids 16 (1973) 1337.

[16] DANDL, R.A., et al., Plasma confinement and heating in the ELMO Bumpy Torus (EBT), in Plasma Physics and Controlled Nuclear Fusion Research (Proc. 5th Conf. Toyko, 1974) II, IAEA, Vienna (1975) 141.

[17] DANDL, R.A., et al., "Research Program for Plasma Confinement and Heating in ELMO Bumpy Torus Devices," Oak Ridge National Laboratory, ORNL-TM-4941 (June 1975).

[18] GOLANT, V.E., et al., Zh. Tekh. Fiz. [Sov. Phys.-Tech. Phys.] 17 (1972) 488.

[19] ALIKAEV, V.V., et al., Pis'ma v Žh. Ehksp. Teor. Fiz. 15 (1972) 41.

[20] ALIKAEV, V.V., et al., Investigation of the electron energy distribution function and its variation during electron-cyclotron resonance heating, in Plasma Physics and Controlled Nuclear Fusion Research, Nucl. Fusion Supplement 33 (1974). 
[21] ALIKAEV, V.V., et a1., Sov. J. P1asma Phys. I (1975) 303.

[22] LITVAK, A.G., et al., Sov. Tech. Phys. Lett. I (1975) 374.

[23] AlikaeV, V.V., et al., Fiz. Plazmy 2 (1976) 390.

[24] ALIKAEV, V.V., et al., Fiz. Plazmy $\underline{3}$ (1977) 230.

[25] LITVAK, A.G., et a7., Nucl. Fusion 17 (1977) 659.

[26] GOLANT, V.E., PILIYA, A.D., Usp. Fiz. Nauk [Sov. Phys.-Usp.] 14 (1972) 413.

[27] EROKHIN, N.S., MOISEEV, S.S., Usp. Fiz. Nauk [Sov. Phys.-Usp.] 16 (1973) 64 .

[28] GOLANT, V.E., PILIYA, A.D., Microwave heating of plasma, in Problems of Modern Physics, Nauka, Leningrad (1974) 92.

[29] PILIYA, A.D., FEDOROV, V.I., Sov. Phys.-JETP 33 (1971) 210.

[30] SCHUSS, J.J., HOSEA, J.C., Phys. Fluids 18 (1975) 727.

[31] PREINHAELTER, J., KOPECK'Y, V., J. Plasma Phys. 10 (1973) 1.

[32] BEKEFI, G., Radiation Processes in Plasmas, John Wiley and Sons, Inc. (1966), Chap. 7.

[33] STIX, T.H., The Theory of Plasma Waves, McGraw-Hill Book Co., Inc. (1962), Sect. 9-16.

[34] GOLANT, V.E., Zh. Tekh. Fiz. [Sov. Phys.-Tech. Phys.] 16 (1972) 1980.

[35] GLAGOLEV, V.M., Plasma Phys. 14 (1972) 301, 315.

[36] PURI, S., TUTTER, M., NUCl. Fusion 14 (1974) 93.

[37] STIX, T.H., op. cit., Sect. 1-6.

[38] AKHIEZER, A.I., AKHIEZER, I.A., POLOVIN, R.V., SITENKO, A.G., STEPANOV, K.N., Plasma Electrodynamics, Pergamon Press (1975), Chap. 5. 
[39] KUCKES, A.D., Plasma Phys. 10 (1968) 367.

[40] GRAWE, H., Plasma Phys. 11 (1969) 151.

[41] L.ICHTENBERG, A.J., SCHWARTZ, M.J., PTasma Phys. 11 (1969) 101.

[42] KAWAMURA, T., Nucl. Fusion 11 (1971) 339.

[43] Lieberman, M.A., LiChTEnberg, A.J., Phys. Rev. A $\underline{5}$ (1972) 1852.

[44] TIMOFEEV, A.V., Sov. J. Plasma Phys. 1 (1975) 47.

[45] CANOBBIO, E., Nucl. Fusion $\underline{9}$ (1969) 27.

[46] ELDRIDGE, 0.C., Phys. Fluids 15 (1972) 676.

[47]. AKHIEZER, A.I., BAKAI, A.S., Sov. J. Plasma Phys. 2 (1976) 359.

[48] FERMI, E., Phys. Rev. 75 (1949) 1169.

[49] ChANDRASEKHAR, S., Rev. Mod. Phys. 15 (1943) 1.

[50] IKEGAMI, H., AIHARA, S., HOSOKAWA, M., AIKAWA, H., Nucl. Fusion $\underline{13}$ (1973) 351 .

[51] BARTER, J.D., SPROTT; J.C., WONG, K.L., Phys. Fluids 17 (1974) 810.

[52] GUEST, G.E., SIGMAR, D.J.., NUCl. Fusion 11 (1971) 151.

[53] DANDL, R.A., et al., Nucl. Fusion 11 (1971) 411 .

[54] IKEGAMI, H., et al., Characteristics of microinstabilities in a hot-electron plasma, in Plasma Phyșics and Controlled Nuclear Fusion Research (Proc. 3rd Conf. Novosibirsk, 1968) II, IAEA, Vienna (1969) 423:

[55] ALIKAEV, V.V., RA7IIMQVA, K.A., SOKOLOV, YU.^., SOV. J. Plasma Phys. 1 (1975) 303.

[56] GUEST, G.E., HEDRICK, C.L., NELSON, D.B., Phys. Fluids 18 (1975) 871 .

[57] STIX, T.H., op. cit., p. 211.

[58] :- BERK, H.L., Phys. Fluids 19 (1976) 1255. 
[59] GOLANT, V.E., et. al., in Proc. 6th European Conf. on Controlled Fusion and Plasma Physics (Moscow, 1973) I, 587.

[60] ANISIMOV, A.I., et al., Plasma research with the Tuman-2 device, Plasma Physics and Controlled Nuclear Fusion Research, Nucl. Fusion Supplement 321 (1972).

[61] ALIKAEV, V.V., BOBROVSKI, G.A., POZNIAK, V.J., RAZUMOVA, K.A., SANIKOV, V.V., SOKOLOV, Yu.A., SHMARIN, Physica Plasmi $\underline{3}$ (1976) 390.

[62] ARTSIMOVICH, L.A., Controlled Thermonuclear Reactions, Gordon and Breach Scientific Publications; Inc., (1964), 242.

[63] DANDL, R.A., et al., High-beta relativistic electron plasmas in axisymmetric and non-axisymmetric mirrors, in Plasma Physics and Controlled Nuclear Fusion Research (Proc. 4th Conf. Madison, 1971) II, IAEA, Vienna (1971) 607.

[64] DANDL, R.A., et al., Nucl. Fusion 13 (1973) 693.

[65] KADOMTSEV, B.B., in Plasma Physics and the Problems of Controlled Thermonuclear Reactions, ed. by M.A. Leontovich and J. Turkevich, Pergamon Press (1960), 4 , 17.

[66] GUEST, G.E., HEDRICK, C.L., NELSON, D.B., "On the Interchange Stability of a Guiding-Center Plasma In An Axisymmetric Magnetic Trap," Oak Ridge National Laboratory, ORNL/TM-4077 (December 1972); NELSON, D.B., HEDRICK, C.L., SPIES, G.O., "The Stability of Anisotropic Equilibria In Closed Line Tori," Oak Ridge National Laboratory, ORNL/TM-4109 (March 1973).

[67] MOROZOV, A.I.,. SOLOV'EV, L.S., Review of Plasma Physjcs, ed. by Acad. M.A. Leontovich, Consultants Bureau (1966), 2, 267-272. 
[68] KOVRIZHNYKH, L.M., Zh. Eksp. Teor. Fiz. [Sov. Phys.-JETP] 29 (1969) 475.

[69] YOSHIKAWA, S., ROSE, D., Phys. Fluids $\underline{5}$ (1962) 334.

[70] QUON, B.H., DANDL, R.A., COLESTOCK, P.L., IKEGAMI, H., "Effects of Global Field Errors on ELMO Bumpy Torus," Oak Ridge National Laboratory, ORNL/TM-6075 (October 1977).

[71] MCALEES, D.G., et al., "The ELMO Bumpy Torus Reactor (EBTR) Reference Design," Dak Ridge National Laboratory, ORNL/TM-5669 (November 1976).

[72] OKRESS, E.C., Microwave Power Engineering, Academic Press (1968), Vol. 1, Chap. 3.

[73] SILVER, S., Ed., Microwave Antenna Theory and Design, MIT Radiation Laboratory Series, McGraw-Hill (1949), Vol. 12, Chap. 10.

[74] EASON, H.0., Jr., "Microwave Formation and Heating of Plasmas for Controlled Fusion Research," J. Micrnwave Power $\underline{4}$ (2) (1969) 88-99.

[75] HIRSHFiELD, J.L., and WACHTEL, J.M., "Electron Cyclotron Maser," Phys. Rev. Lett. 12 (1964) 533-536.

[76] ZAYTSEV, N.I., PANKRATOVA, T.B., PETEL IN, M.I., and FLYAGIN, V.A., "Millimeter- and Submillimeter-Wave Gyrotrons," Radiotekh. Electron. LRadio Eng. Electron. Phys.] 19 (1974) 1056-60. 
ORNL/TM-6703

Dist. Category UC-20 a, d, f, g

INTERNAL DISTRIBUTION

1. F. W. Baity, Jr.

2. J. K. Ballou

3. C. F. Barnett

4. D. B. Batchelor

5. L. A. Berry

6. F. M. Bieniosek

7. A. L. Boch

8. J. D. Callen

9. G. L. Campen

10. J. A. Cobble

11. R. J. Colchin

12. R. A. Dory

13-113. H. 0. Eason

114. P. H. Edmonds

115. A. C. England

116. J. C. Glowienka

117. W. R. Hamilton

118. G. R. Haste

119. C. L. Hedrick, Jr.

120. D. P. Hutchinson

121. R. C. Isler

122. E. F. Jaeger

123. T. C. Jernigan

124. R. A. Langley

125. C. M. Loring

126. J. N. Luton

127. J. F. Lyon

128. H. C. McCurdy

129. A. T. Mense

130. J. T. Mihalczo

131. R. V. Miskell
132. O. B. Morgan, Jr.

133. M. Murakami

134. D. B. Nelson

135. L. W. Owen

136. G. F. Pierce

137. H. Postma

138. R. K. Richards

139. J. A. Rome

140. M. W. Rosenthal

141. M. J. Saltmarsh

142. J. Sheffield

143. D. A. Spong

144. W. L. Stirling

145. J. D. Stout

146. D. W. Swain

147. C. C. Tsai

148. N. A. Uckan

149. T. Uckan

150. T. L. White

151. J. B. Wilgen

152. W. R. Wing

153. W. L. Wright

154. H. T. Yeh

155-156. Laboratory Records Department

157. Laboratory Records, ORNL-RC

158. Y-12 Document Reference Section

159-160. Central Research Library

161. Fusion Energy Division Library

162. Fusion Energy Division Communications Center

163. ORNL Patent Office

\section{EXTERNAL DISTRIBUTION}

164. M. W. Alcock, Culham Laboratory, Abingdon, Oxon, England 0X143DB

165. D. J. Anthony, Energy Systems and Technology Div., General Electric Co., 1 River Rd., Bldg. 23, Rm. 290, Schenectady, NY 12345

166. W. B. Ard, McDonnell Vouglas-East, P.0. Bux 516, St. Louis, M0 63166

167. B. Arfin, Lawrence Livermore Laboratory, University of California, P.O. Box 808, Livermore, CA 94550 
168. K. W. Arnold, Hughes Aircraft Co., Electron Dynamics Div., 3100 W. Lomita BTvd., Torrance, CA 90509

169. D. Arnush, TRW Defense \& Space Systems, 1 Space Park, BTdg. R-1, Redondo Beach, CA 90278

170. C. Baker, Fusion Engineering Department, General Atomic Co., P.0. Box 81608, San Diego, CA 92138

171. R. E. Balzhiser, Electric Power Research Institute, 3412 Hillview Avenue, P.0. Box 10412, Palo Alto, CA 94304

172. W. B. Briggs, McDonnell Douglas - East, P.0. Box 516, St. Louis, M0 63166

173. S. Buchsbaum, Research Communications Principles Division, Bell Telephone Laboratories, Inc., Murray Hill, NJ 07974

174. J. A. Christensen, Hughes Aircraft Co., Electron Dynamics Div., 3100 W. Lomita Blvd., Torrance, CA 90509

175. Centre de Recherches en Library, Physique des Plasmas, 21 Avenue des Bains, 1007 Lausanne, Switzerland

176. M. Clark, Combusion Engineering, Windsor, CT 06095

177. J. F. Clarke, Office of Fusion Energy (ETM), G-234, Department of Energy, Washington, DC 20545

178. F. H. Coensgen, University of California, Lawrence Livermore Laboratory, P.0. Box 808, Livermore, CA 94550

179. F. E. Coffman, Office of Fusion Energy (ETM), Department of 'Energy, Washington, DC 20545

180. P. L. Colestock, Plasma Physics Laboratory, Princeton University, P.0. Box 451, Princeton, NJ 08540

181. D. Cohn, Massachusetts Institute of Technology, Cambridge, MA 02139

182. R. W. Conn, University of Wisconsin, Dept. of Nuclear Enyilleeriny, Madison, WI 53706

183. T. Consoli, Centre d'Etudes Nucleaires de Grenoble, B.P. 85 Centre de Tri, 38041 Grenoble Cedex, Grenoble, France

184. E. C. Creutz, Bishop Museum, P.0. 6037, Honolulu,. HI 96818

185. F. L. Culler, Electric Power Research Institute, 3412 Hillview Avenue, P.0. Box 10412, Palo Alto, CA 94304

186. R. A. Dand1, 1122 Calle de Los Serranos, San Marcos, CA 92069 
187. J. M. Dawson, Dept. of Physics, University of California, Los Angeles, CA 90024

188. R. DeBellis; Sr., McDonnell Douglas - East, P.0. Box 516, St. Louis, M0 63166

189. H. W. Deckman, Advanced Energy Systems Laboratory, Government Research Laboratories, Exxon Research and Engineering Co., P.0. Box 8, Linden, NJ 07036

190. A. N. Dellis, Culham Laboratory, Abingdon, Oxfordshire, England 0x14 3DB

191. H. Derfler, Max Planck Institute fur Plasmaphysik, 8046 Garching bei Munchen, West Germany

192. D. A. Dingee, Manager, Fusion Programs, Battelle-Northwest, Battelle Blvd., P.0. Box 999, Richland, WA 99352

193. H. Dreicer, Group CTR-1, Los Alamos Scientific Laboratory, P.0. Box 1663, Los Alamos, NM 87545

194. R. E. Edwards, Raytheon Company, Microwave and Power Tube Div., Waltham, MA 02154

195. P. C. Efthimion, Princeton Plasma Physics Laboratory, Princeton Univ., P.0. Box 451, Princeton, NJ 08540

196. R. A. Ellis, Princeton Plasma Physics Lab., Princeton University, P.0. Box 451, Princeton, NJ 08540

197. W. R. Ellis, Jr., Office of Fusion Energy (ETM), G-234, Department of Energy, Washington, DC 20545

198. H. H. Fleischmann, Dept. of Applied Physics, Clark Hal1, Cornell Univ., Ithaca, NY 14853

199. M. Fontenas1, Laboratorio di Fisica D'el Plasma, Ass. CNR EURATOM via Bassini 15, Milano, Italy.

200. H. K. Forsen, Exxon Nuclear Co., 777 106th Ave., NE, Bellevue, WA 98009

201. J. Foster, TRW Defense and Space Systems, 1 Space Park, B1dg. R-1, Redondo Beach, CA 90278

202. T. K. Fowler, L-382, University of California, Lawrence Livermore Laboratory, P.0. Box 808, Livermore, California 94550

203. M. Fujiwara, Institute of Plasma Physics, Nagoya Univ., Nagoya $\underline{464}$, Japan

204. H. P. Furth, Princeton University, Plasma Physics Lab., P.0. Box 451, Princeton, NJ. 08540 
205. Fusion Power Program, Argonne National Laboratory, 9700 S. Cass Ave., Argonne, IL 60439

206. M. B. Gottlieb, Princeton University, Plasma Physics Lab., P.0. Box 451, Princeton, NJ 08540

207. R. W. Gould, California Institute of Technology, M/S 116-81, Pasadena, CA 91109

208. H. Grad, New York University, Courant Institute of Mathematical Sciences, Magneto-Fluid Dynamics Div., 251 Mercer St., New York, NY 10012

209. V. Granatstein, Naval Research Laboratory, Code 7740, Washington, DC 20375

210. A. Grant, TRW Defense and Space Systeins, 1 Space Park, BTdg. R-1, Redondo Beach, CA 90278

211. G. E. Guest, General Atomic Company, P.0. Box 81608, San Diego, CA 92138

212. G. M. Haas, Office of Fusiun Energy (ETM), Mail Stop G-234, Department of Energy, Washington, DC 20545

213. E. G. Harris, Dept. of Physics, Univ. of Tennessee, Knoxville, TN 37916

214. I. G. Hedrick, M/S C-0405, Grumman Aerospace Corporation, Bethpage, NY $11 / 14$

215. G. K. Hess, Jr., Office of Fusion Energy (ETM), G-234, Department of Energy, Washington, DC 20545

216. M. E. Hesse, Centre d'Etudes Nucleaires de Grenoble, B.P. 85, Centre de Tri, 38041 Grenoble Cedex, Grenoble, France

217. R. L. Hickok, Rensselaer Polytechnic Institute, ESE Dept., Troy, NY 12181

218. A. G. Hill, Massachusetts Insitute of lechnology, Cambridge, MA Ol23y

219. S. Hiroe, Institute of Plasma Physics, Nagoya University, Nagoya 464, Japan

220. R. L. Hirsch, Exxon Corporation, Science and Technology Dept., 1251 Ave. of the Americas New York, NY 10020

221. J. Hosea, P1asma Physics Laboratory, Princeton University, P.0. Box 451, Princeton, NJ 08540

222. H. C. Hsuan, Princeton Plasma Physics Laboratory, Princeton University, P.0. Box 457, Princeton, NJ 08540 
223. B. Hui, Science Applications, Inc., 1200 Prospect Street, Box 2351, La Jolla, CA 92037

224. S. Humphries, Laboratory of Plasma Physics, 308 Upson Hall, Cornell University, Ithaca, NY 14853

225. R. Huse, Chairman, EPRI Fusion Program Committee, Public Service and Gas Co., 80 Park Place, Newark, NJ 07101

226. H. Ikegami, Institute of Plasma Physics, Nagoya University, Nagoya 464 , Japan

227. H. R. Jory, Varian Associates, 611 Hansen Way, Palo Alto, CA 94303

228. A. Kadish, Office of Fusion Energy (ETM), G-234, Department of Energy, Washington, DC 20545

229: J. Killeen, University of California, Lawrence Livermore Laboratory, P.0. Box 808, Livermore, CA 94550

230. E. E. Kintner, Director, Office of Fusion Energy (ETM), G-234, Department of Energy, Washington, DC 20445

231. N. A. Kral1, Science Applications, Inc.; 1200 Prospect Street, Box 2351 , La Jolla, CA 92037

232. S. P. Kuo, Dept. of Electrical Engineering, Polytechnic Irístitute of New York, 333 Jay Street, Brooklyn, NY 11201

233. N. H. Lazar, TRW Defense \& Space Systems, I Space Park, Bldg. R-1, Redondo Beach, CA 90278

234. E. Lee, Controlled Thermonuclear Research Division, Lawrence Livermore Laboratory, P.0. Box 808, Livermore, CA 94550

235. Librarian, Institut fur Plasma Physik, 8046 Garching Bei Munchen, Federal Republir. of Germany

236. Librarian, CuTham Laboratory, UK Atomic Energy Authority, Abingdon, Berks., England

237. Library, Centre de Recherches en Physique des Plasmas, 21 Avenue des Bains, 1007 Lausanne, Switzerland

238. G. Logan, Controlled Fusion Group, L-386, Lawrence Livermore Lab., University of California, P.0. Box 808, Livermore, CA 94550

239. D. G. McAlees, Exxon Nuclear Co., Inc., Research \& Technology Center;: Laser Enrichment Dept., 2955 George Washington Way, Richland, WA 99352

240. T. Menne, McDonne11 Douglas-East, P.0. Box 516, St. Louis, M0 63166 
241. C. Moeller, General Atomic Co., P.0. Box 81608, San Diego, CA 92138

242. R. Moir, University of California, Lawrence Livermore Laboratory, P.0. Box 808, Livermore, CA 94550

243. K. G. Moses, TRW Defense and Space Systems, I Space Park, BIdg. R-1, Redondo Beach, CA 90278

244. J. H. Mullen, McDonnell Douglas - East, P.0. Box 516, St. Louis, MO 63166

245. M. R. Murphy, Office of Fusion Energy (ETM), Mail Stop G-234, Department of Energy, Washington, DC 20545

246. S. Naymark, Nuclear Services Corporation, 1700 De11 Avenue, Campbe11, CA 95008

247. J. 0. Neff, Office of Fusion Energy (ETM), Mail Stop G-234, Department of Energy, Washington, DC 20545

248. T. Ohkawa, General Atomic Co., P.0. Box 81608, San Diego, CA 92138

249. R. R. Parker, Massachusetts Institute of Technology, Nw 14-124, Cambridge, MA 02139

250. L. D. Pearlstein, Lawrence Livermore Laboratory, P.0. Box 808, Livermore, CA 94550

251. Plasma Physics Library, Plasma Physics Laboratory, Princeton University, P.0. Box 451, Princeton, NJ 08540

252. R. E. Price, Chief, Fusion Plasma Theory Branch, Office of Fuston Energy (ETM), Mail Stop G-234, Department of Energy, Washington, DC 20545

253. B. H. Quon, TRW Defense \& Space Systems, 1 Space Park, Bldg. R-1, Rm. 1070, Redondo Beach, CA 90278

254. M. E. Read, Plasma Physics Div., Bldg. 101, Naval Research Laboratory, Washington, DC 20375

255. D. J. Rose, Department of Nuclear Engineering, Massachusetts Instutite of Technology, Cambridge, MA 02139

256. S. P. Schlesinger, Naval Research Laboratory, Code $7 / 40$, Washington, DC 20545

257. F. R. Scott, Electric Power Research Institute, 3412 Hillview Ave., P.0. Box 10412, Palo Alto, CA 94304

258. Z. M. Shapiro, Westinghouse Electric Co., P.0. Box 355, Pittsburgh, PA 15230 
259. L. D. Smuilin, Rm. 38-294, Plasma Fusion Center, Massachusetts Institute of Technology, Cambridge, MA 02139

260. P. A. Sprangle, Naval Research Laboratory, Plasma Physics Div., Code 7750, Washington, DC 20375

261. W. M. Stacy, Jr., School of Nuclear Engineering, Georgia Institute of Technology, Atlanta, GA 30332

262. A. Staprans, Varian Associates, 611 Hansen Way, Palo Alto, CA 94303

263. H. S. Staten, Office of Fusion Energy (ETM), Mail Stop G-234, Department of Energy, Washington, DC 20545

264. P. Staudhammer, TRW Defense and Space Systems, 1 Space Park, Bldg. R-1, Redondo Beach, CA 90278

265. C. M. Stickley, Laser Fusion, Department of Energy, Washington, DC 20545

266. P. M. Stone, Office of Fusion Energy, Mail Stop G-234, Department of Energy, Washington, DC 20545

267. Donald Sweetman, Culham Laboratory, Abingdon, 0xfordshire, England $0 \times 14$ $3 \mathrm{DB}$.

268. R. S. Symons, Varian Associates, 611 Hansen Way, Palo Alto, CA 94303

269. F. Thomas, Grumman Aerospace Corp., Department 930, PLT 5, Bethpage, NY 11714

270. A. W. Trivelpiece, Exxon Nuclear Co., Inc., Research \& Technology Center, 2955 George Washington Way, Richland, WA 99352

271. W. C. Turner, Lawrence Laboratory, P.0. Box 808, Livermore, CA 94550

272. C. von Keszycki, Grumman Aerospace Corp., Department 930, PLT 5, Bethpage, NY 11714

273. J. W. Willis, Office of Fusion Energy, Mail Stop G-234, Department of Energy, Washington, DC 20545

274. D. Zuckerman, McDonnell Douglas - East, P.0. Box 516, St. Louis, MO 63166

275. Office of Assistant Manager, Energy Research and Development, Department of Energy, Oak Ridge Operations Office, P.O. Box E, Oak Ridge, TN 37830

276- Given Distribution as shown in TID 4500, Magnetic Fusion Energy (Distri-

590. bution Category UC-20 a, d, f, g: Plasma Systems, Fusion Systems, Experimental Plasma Physics, and Theoretical Plasma Physics 